Y. Yamada

Nagoya Math. J.

Vol. 84 (1981), 31-83

\title{
QUASILINEAR WAVE EQUATIONS AND RELATED NONLINEAR EVOLUTION EQUATIONS*
}

\author{
YOSHIO YAMADA
}

\section{Introduction}

In this paper we consider the relations between quasilinear wave equations

$$
u_{t t}-\sum_{i, j=1}^{n} a_{i j}(\operatorname{grad} u) u_{i j}+c u_{t}=f,
$$

and related third-order differential equations

$$
u_{t t}-\lambda \Delta u_{t}-\sum_{i, j=1}^{n} a_{i j}(\operatorname{grad} u) u_{i j}+c u_{t}=f,
$$

( $\lambda$ is a positive parameter) with the same initial conditions

$$
\left\{\begin{array}{l}
u(x, 0)=u_{0}(x), \\
u_{t}(x, 0)=v_{0}(x),
\end{array}\right.
$$

where $x=\left(x_{1}, x_{2}, \cdots, x_{n}\right), t \geqq 0, u=u(x, t), u_{t}=\partial u / \partial t, u_{t t}=\partial^{2} u / \partial t^{2}, u_{i}=$ $\partial u / \partial x_{i}, u_{i j}=\partial^{2} u / \partial x_{i} \partial x_{j}, \operatorname{grad} u=\left(u_{1}, u_{2}, \cdots, u_{n}\right)$ and $\Delta u=\sum_{i=1}^{n} u_{i i}$. In equations (1) and (2), $c$ is a real number and $a_{i j}=a_{j i}(i, j=1,2, \cdots, n)$ are real smooth functions satisfying

$$
\sum_{i, j=1}^{n} a_{i j}(\eta) \xi_{i} \xi_{j} \geqq a_{0}(\rho)|\xi|^{2}, \quad|\xi|^{2}=\sum_{i=1}^{n} \xi_{i}^{2},
$$

for every $\eta \in R^{n},|\eta| \leqq \rho$ and $\xi \in R^{n}, a_{0}(\rho)$ being a positive non-increasing function.

Equations of type (2) were first proposed by Greenberg, MacCamy and Mizel [7] in the case $n=1$. They have dealt with equations of the form

$$
u_{t t}-\sigma\left(u_{x}\right) u_{x x}-\lambda u_{x t x}=0, \quad \lambda>0,
$$

to approach quasilinear wave equations for a nonlinear string model

Received November 28, 1979.

* Partially supported by Yukawa Fellowship. 


$$
u_{t t}-\sigma\left(u_{x}\right) u_{x x}=0,
$$

where $\sigma$ is a positive smooth function. Their idea is based on the viscosity method; $-\lambda u_{x t x}$ in (4) may be considered as a viscosity term and the limiting procedure $\lambda \downarrow 0$ will enable to find a solution of (4). However, they have not obtained any relations between (4) and (5), although they have established the technics to treat equation (4).

In Chapter I, we give a systematic study of equations (2) with initial conditions (3). Mixed problems for equations of the form (2) have been considered by several authors, Cleménts [1], Ebihara [4], [5], Tsutsumi [19], Yamada [20] and Kozhanov, Lar'kin and Janenko [25]. However, their technics are based on the Galerkin's method, which is not applicable to our initial value problems. To overcome this difficulty, it is necessary to seek a new approach. Our idea is to reduce the original problems to the initial value problems for abstract evolution equations in a suitable Hilbert space, so that general theory for evolution equations may be applied.

We introduce the usual Sobolev space $H^{m}$ of order $m$, where $m$ is an integer such that $m \geqq[n / 2]+1$. By defining a negative self-adjoint operator $A$ by

$$
A u=(\Delta-1) u \quad \text { for } u \in D(A)=H^{m+2},
$$

$(D(A)=$ domain of $A)$, initial value problem (2), (3) can be written as

$$
\left\{\begin{array}{l}
u_{t t}-\lambda A u_{t}-B(u)+(c-\lambda) u_{t}=f, \quad t \geqq 0, \\
u(0)=u_{0}, \quad u_{t}(0)=v_{0},
\end{array}\right.
$$

where

$$
B(u)=\sum_{i, j=1}^{n} a_{i j}(\operatorname{grad} u) u_{i j} .
$$

Now it is very convenient to introduce two unknown functions $v(t)$ and $w(t)$ by

$$
v(t)=u_{t}(t) \quad \text { and } w(t)=A u(t) .
$$

Then (6) is rewritten in the following form

$$
\left\{\begin{array}{l}
U_{t}(t)=A U(t)+B(U(t))+F(t), \quad t \geqq 0 \\
U(0)=U_{0} \equiv{ }^{t}\left(v_{0}, A u_{0}\right)
\end{array}\right.
$$

where 


$$
U=\left(\begin{array}{l}
v \\
w
\end{array}\right), \quad A=\left(\begin{array}{cc}
\lambda A & 0 \\
A & 0
\end{array}\right), \quad \boldsymbol{B}(U)=\left(\begin{array}{c}
B\left(A^{-1} w\right)+(\lambda-c) v \\
0
\end{array}\right), \quad F=\left(\begin{array}{l}
f \\
0
\end{array}\right) .
$$

It is possible to show that $\boldsymbol{A}$ generates an analytic semi-group of bounded linear operators, $T(t), t \geqq 0$, on $H^{m} \times H^{m}$ and that $\boldsymbol{B}(U)$ is a locally bounded and Lipshitz continuous operator in $H^{m} \times H^{m}$. Therefore, the differential equation in (7) may be regarded as a semilinear evolution equation of parabolic type. Moreover, initial value problem (7) becomes equivalent to the following integral equation

$$
U(t)=T(t) U_{0}+\int_{0}^{t} T(t-s)(B(U(s))+F(s)) d s .
$$

It is not so difficult to solve (8); for example, it suffices to make use of the fixed point theorem to obtain the local existence of a solution for (8). Hence, returning to the original problem, we can get the local existence result of solutions to (2). To extend a local solution $u$ to an appropriate interval, it is sufficient to derive a priori estimates for $u$ by the usual energy method. In general, the existence interval depends on $u_{0}, v_{0}$ and $f$.

Especially, to extend a local solution $u$ to the whole interval $[0, \infty)$, we have to get some a priori bounds for $u$ on $[0, \infty)$. Roughly speaking, this is possible if $c$ is positive and the data $\left(u_{0}, v_{0}, f\right)$ are sufficiently small in a sense. Thus, we can get sufficient conditions under which initial value problem (2), (3) has a global solution $u$. Moreover, as is expected from the presence of the dissipative term $c u_{t}(c>0)$, the global solution $u$ does decay to zero as $t \rightarrow \infty$ when $f \equiv 0$. The weighted energy method yields precise decay estimates of such $u$.

In Chapter II we shall establish the existence results for initial value problems (1), (3) by making use of the existence results for initial value problems (2), (3). One of the typical examples of equations (1) is the following

$$
u_{t t}-\sum_{i=1}^{n} \frac{\partial}{\partial x_{i}}\left(\frac{u_{i}}{\sqrt{1+|\operatorname{grad} u|^{2}}}\right)+c u_{t}=f,
$$

which describes the nonlinear vibration of a string for $n=1$ and that of a membrane for $n=2$.

Though there are a number of researches on the quasilinear wave equations (see e.g. Dionne [3] and Sobolev [18]), our approach based on 
the viscosity method seems very new.

We now explain our idea. Let $u^{\lambda}$ be a solution of initial value problem (2), (3) (we put the superscript $\lambda$ to specify the dependence of $\lambda$ ). It is natural to expect that $u^{\lambda}$ will converge (in an appropriate sense) to a function as $\lambda \downarrow 0$ and that the limit function $u^{0}$ will become a solution of initial value problem (1), (3).

It is true that the local existence result in Chapter I assures the existence of a local solution $u^{\lambda}$ of (2) and (3). But this is unsatisfactory, because the local existence interval $[0, \tau]$ with some $\tau>0$ also depends on $\lambda$ and $\tau=\tau(\lambda)$ may tend to zero as $\lambda \downarrow 0$. Therefore, one needs to carry out more delicate calculations than in Chapter I. By employing the energy method, it is possible to show the existence of an interval $\left[0, T_{0}\right]$, independent of $\lambda$, on which any solution of (2) and (3) has a priori bounds independent of $\lambda$. This assures the continuation of a local solution $u^{\lambda}$ of (2) and (3) to $\left[0, T_{0}\right]$.

It is in the standard way to prove that there exists a function $u^{0}(t)$ $=\lim _{2 \downarrow 0} u^{\lambda}(t)$ for $0 \leqq t \leqq T_{0}$ (in a certain sense) and that the limit function $u^{0}$ is a solution of (1) and (3) on [0, $\left.T_{0}\right]$. Our local existence result for (1), (3) obtained in this way is not new, but the approach via the viscosity method seems simpler than the existing one due to Dionne [3].

When $c$ is positive, we can also get the global existence result as in the case of initial value problem (2), (3). The smallness condition on the data $\left(u_{0}, v_{0}, f\right)$ yields some a priori estimates for the solution to (1) and (3), which enables the extension of the local existence interval to $[0, \infty)$. In this sense, the dissipative term $c u_{t}$ plays a role to stabilize solutions to (1). Furthermore, it has a damping effect on solutions. In fact, if $f \equiv$ 0 , one can derive the rate of the decay to zero for solutions to (1) as $t \rightarrow \infty$.

In this paper our investigation is restricted to equations of the forms (1) and (2). But the methods presented here can be applied essentially in the same way to equations of more general forms

$$
u_{t t}-\lambda \Delta u_{t}-\sum_{i, j=1}^{n} a_{i j}\left(x, t, u, \operatorname{grad} u, u_{t}\right) u_{i j}+b\left(x, t, u, \operatorname{grad} u, u_{t}\right)=f,
$$

and

$$
u_{t t}-\sum_{i, j=1}^{n} a_{i j}\left(x, t, u, \operatorname{grad} u, u_{t}\right) u_{i j}+b\left(x, t, u, \operatorname{grad} u, u_{t}\right)=f
$$


The author wishes to express his hearty thanks to Professor H. Tanabe, K. Maruo and A. Yagi for stimulating conversations. Also, the hospitality of Osaka University during the preparation of the manuscript is gratefully acknowledged.

\section{Notation}

We summarize some notation which will be used throughout this paper.

Let $x=\left(x_{1}, x_{2}, \cdots, x_{n}\right) \in R^{n}$ and $d x=d x_{1} d x_{2} \cdots d x_{n}$. Functions appearing in the present paper are all real (without their Fourier transforms). As usual, denote by $L^{p}(1 \leqq p \leqq \infty)$ the space of all measurable functions on $R^{n}$ such that

$$
\begin{aligned}
& \|u\|_{L^{p}}=\left(\int_{R^{n}}|u(x)|^{p} d x\right)^{1 / p} \quad \text { if } 1 \leqq p<\infty, \\
& \|u\|_{L^{\infty}}=\operatorname{ess~sup}_{x \in R^{n}}|u(x)| \quad \text { if } p=\infty .
\end{aligned}
$$

If $p=2, L^{2}$ is a Hilbert space with the inner product

$$
(u, v)=\int_{R^{n}} u(x) v(x) d x .
$$

For simplicity, we write $\|\cdot\|$ in stead of $\|\cdot\|_{L^{2}}$.

Let $k$ be an integer $\geqq 1$. The Sobolev space $H^{k}$ of order $k$ on $R^{n}$ is defined by

$$
H^{k}=\left\{u ; D_{x}^{\alpha} u \in L^{2} \text { for any } \alpha \text { such that }|\alpha| \leqq k\right\},
$$

where

$$
D_{x}^{\alpha}=\frac{\partial^{\alpha_{1}+\cdots+\alpha_{n}}}{\partial x_{1}^{\alpha_{1}} \cdots \partial x_{n}^{\alpha_{n}}}, \quad \alpha=\left(\alpha_{1}, \cdots, \alpha_{n}\right), \quad|\alpha|=\alpha_{1}+\cdots+\alpha_{n},
$$

and the derivatives are taken in the sense of distributions. We provide $H^{k}$ with the inner product

$$
(u, v)_{k}=\sum_{|\alpha| \leqq k}\left(D_{x}^{\alpha} u, D_{x}^{\alpha} v\right)
$$

and the norm

$$
\|u\|_{k}^{2}=(u, u)_{k}^{2} .
$$

An equivalent definition of $H^{k}$ is given with the use of the Fourier transform. If $u \in L^{2}$, the Fourier transform $\hat{u}$ in $L^{2}$ is defined by 


$$
\hat{u}(\xi)=(2 \pi)^{-n / 2} \int_{R^{n}} e^{-i \xi \cdot x} u(x) d x, \quad \xi \cdot x=\sum_{i=1}^{n} \xi_{i} x_{i},
$$

where the integral convergence is taken in the sense of $L^{2}$. Then

$$
H^{k}=\left\{u ;(1+|\xi|)^{k} \hat{u} \in L^{2}\right\} \text {. }
$$

Denote by $C_{0}^{\infty}$ the space of all infinitely differentiable functions with compact support. It is well known that $C_{0}^{\infty}$ is dense in $H^{k}$ for any $k$.

Let $I$ be any subinterval of $[0, \infty)$ and let $X$ be any Banach space. We denote by $C(I ; X)$ (resp. $C_{w}(I ; X)$ ) the space of all functions $u$ such that $u$ is strongly (resp. weakly) continuous from $I$ to $X . \quad C^{j}(I ; X)$ (resp. $\left.C_{w}^{j}(I ; X)\right)$ denotes the space of all functions $u \in C(I ; X)$ (resp. $C_{w}(I ; X)$ ) such that $u$ is $j$-times strongly (resp. weakly) continuously differentiable from $I$ to $X$. We provide $C^{j}(I ; X)$ with the uniform (strong) convergence topology on $I$.

\section{Chapter I. Nonlinear Evolution Equations with Strong Dissipative Terms}

\section{§1. Problems and results}

In this paper we consider initial value problems for the following differential equations

$$
\begin{gathered}
u_{t t}-\lambda \Delta u_{t}-\sum_{i, j=1}^{n} a_{i j}(\operatorname{grad} u) u_{i j}+c u_{t}=f, \quad x \in R^{n}, \quad t \geq 0 \\
u(x, 0)=u_{0}(x), \quad x \in R^{n}, \\
u_{t}(x, 0)=v_{0}(x), \quad x \in R^{n},
\end{gathered}
$$

where $\lambda$ is a positive constant and $c$ is a real number. We sometimes call the linear term $-\lambda \Delta u_{t}$ a "strong dissipative term". (This terminology is due to Ebihara [4]).

An equation of type (1.1) was first proposed by Greenberg, MacCamy and Mizel [7] for $n=1$. They considered equations of the form

$$
u_{t t}-\sigma\left(u_{x}\right) u_{x x}-\lambda u_{x t x}=0, \quad \lambda>0,
$$

to approach quasilinear wave equations of the form

$$
u_{t t}-\sigma\left(u_{x}\right) u_{x x}=0,
$$


where $\sigma$ is a positive smooth function (see also the works of MacCamy and Mizel [11] and Kozhanov, Lar'kin and Janenko [25]). For general $n \geqq 2$, equations of type (1.1) have been treated by Cleménts [1], Ebihara [4], [5], Tsutsumi [19] and Yamada [20]. However, problems treated by them are mixed ones in a bounded domain with the Dirichlet boundary condition. The initial value problems (1.1)-(1.3) have not been solved yet.

Throughout this paper we assume the following. Put $N=[n / 2]+1$ ([ $\cdot]$ denotes the Gaussian bracket) and let $m$ be a positive integer satisfying $m \geqq N$.

(A.1) $a_{i j}(\eta)$ belongs to the class $C^{m+1}\left(R^{n}\right)$ for every $i, j=1,2, \cdots, n$.

(A.2) $a_{i j}(\eta)=a_{j i}(\eta)$ for every $\eta \in R^{n}$ and $i, j=1,2, \cdots, n$.

(A.3) There exists a positive non-increasing function $a_{0}$ satisfying

$$
\sum_{i, j=1}^{n} a_{i j}(\eta) \xi_{i} \xi_{j} \geqq a_{0}(\rho)|\xi|^{2}, \quad|\xi|^{2}=\sum_{i=1}^{n} \xi_{i}^{2},
$$

for every $\eta \in R^{n},|\eta| \leqq \rho$ and $\xi \in R^{n}$.

Now we begin with the local existence theorem for (1.1)-(1.3).

Theorem I (local existence). Let $u_{0} \in H^{m+2}, v_{0} \in H^{m}$ and $f \in C^{1}([0, \infty)$; $\left.H^{m}\right)$. Then there exists a positive constant $\tau$ such that the initial value problem (1.1)-(1.3) has a unique solution $u$ on $[0, \tau]$ satisfying

$$
u \in C\left([0, \tau] ; H^{m+2}\right) \cap C^{1}\left([0, \tau] ; H^{m}\right) \cap C^{1}\left((0, \tau] ; H^{m+2}\right) \cap C^{2}\left((0, \tau] ; H^{m}\right) .
$$

In particular, $u$ also satisfies

$$
u \in C^{1}\left([0, \tau] ; H^{m+1}\right) \quad \text { if } v_{0} \in H^{m+1},
$$

and

$$
u \in C^{1}\left([0, \tau] ; H^{m+2}\right) \cap C^{2}\left([0, \tau] ; H^{m}\right) \quad \text { if } v_{0} \in H^{m+2} .
$$

As to the global existence of solutions to (1.1)-(1.3), we have

Theorem II (global existence). Assume that $c$ is positive. Let $u_{0} \epsilon$ $H^{m+2}, v_{0} \in H^{m+1}$ and $f \in C^{1}\left([0, \infty) ; H^{m}\right) \cap C\left([0, \infty) ; H^{m+1}\right)$. Then there exists $a$ positive number $\delta$ (which depends on $\lambda, c, m, n$ and $D_{\eta}^{\alpha} a_{i j}(|\alpha| \leqq m+1)$ ) such that, if the data $\left(u_{0}, v_{0}, f\right)$ satisfy

$$
\max \left\{\left\|u_{0}\right\|_{m+2},\left\|v_{0}\right\|_{m+1}, \int_{0}^{\infty}\|f(s)\|_{m+1} d s\right\} \leqq \delta,
$$

then the initial value problem (1.1)-(1.3) has a unique solution $u$ on $[0, \infty)$ satisfying 
$u \in C\left([0, \infty) ; H^{m+2}\right) \cap C^{1}\left([0, \infty) ; H^{m+1}\right) \cap C^{1}\left((0, \infty) ; H^{m+2}\right) \cap C^{2}\left((0, \infty) ; H^{m}\right)$.

In addition, $u$ satisfies

$$
\begin{aligned}
& \sup _{t \geqq 0}\|u(t)\|_{m+2}<\infty, \\
& \sup _{t \geqq 0}\left\|u_{t}(t)\right\|_{m+1}<\infty, \\
& \int_{0}^{\infty}\left\|u_{t}(s)\right\|_{m+2}^{2} d s<\infty, \\
& \int_{0}^{\infty}\|\operatorname{grad} u(s)\|_{m+1}^{2} d s<\infty .
\end{aligned}
$$

Theorem II assures the existence of a bounded global solution $u$ of (1.1)-(1.3). So we may investigate the asymptotic property of such a global solution $u$. For simplicity, we set $f \equiv 0$.

Theorem III (asymptotic decay). Assume $c>0$ and $f \equiv 0$. Let $u$ be the solution of (1.1)-(1.3) in Theorem II. Then $u$ decays as follows.

$$
\begin{array}{ll}
\|\operatorname{grad} u(t)\|_{m+1}^{2}=O\left(t^{-1}\right) & \text { as } t \longrightarrow \infty . \\
\left\|u_{t}(t)\right\|_{m+1}^{2}=O\left(t^{-1}\right) & \text { as } t \longrightarrow \infty . \\
\|\Delta u(t)\|_{m}^{2}=O\left(t^{-2}\right) & \text { as } t \longrightarrow \infty . \\
\left\|\operatorname{grad} u_{t}(t)\right\|_{m}^{2}=O\left(t^{-2}\right) & \text { as } t \longrightarrow \infty .
\end{array}
$$

\section{§2. Some Lemmas}

In this section we shall prepare some lemmas which will be used later.

LEMMa 2.1. Let $F, G$ and $H$ be non-negative continuous functions on $[0, T] . \quad$ If

$$
F(t)^{2} \leqq \int_{0}^{t} G(\tau) F(\tau) d \tau+H(t), \quad 0 \leqq t \leqq T
$$

then

$$
F(t) \leqq \frac{1}{2} \int_{0}^{t} G(\tau) d \tau+\sup _{0 \leqq s \leqq t} H(s)^{1 / 2}, \quad 0 \leqq t \leqq T
$$

Proof. Put

$$
X(s)=\int_{0}^{s} G(\tau) F(\tau) d \tau \quad \text { and } \quad H_{\infty}(t)=\sup _{0 \leqq s \leqq t} H(s) .
$$


It follows from the assumption that

$$
\frac{d}{d s}\left(X(s)+H_{\infty}(t)\right)^{1 / 2} \leqq \frac{1}{2} G(s), \quad 0 \leqq s \leqq t .
$$

Integrating the above inequality over $[0, t]$, we obtain the conclusion.

For the Sobolev space $H^{k}$, the following result is well known (see e.g. Mizohata [14] or Sobolev [18]).

Lemma 2.2 (Sobolev's lemma). Let $u \in H^{k}(k \geqq 1)$.

(i) If $k \geqq N \equiv[n / 2]+1$, then, for $|\alpha| \leqq k-N$, $D_{x}^{\alpha} u$ belongs to $\mathscr{B}$ (the space of all bounded continuous functions on $R^{n}$ ). In addition,

$$
\left\|D_{x}^{\alpha} u\right\|_{L^{\infty}} \leqq C\|u\|_{k} \quad \text { for }|\alpha| \leqq k-N,
$$

where $C$ is a positive constant depending on $\alpha, k$ and $n$.

(ii) If $k \leqq N-1$, then $u$ belongs to $L^{p}$ with

$$
\frac{1}{p} \in\left[\frac{1}{2}-\frac{k}{n}, \frac{1}{2}\right]-\{0\} \text {. }
$$

In addition,

$$
\|u\|_{L^{p}} \leqq C\|u\|_{k}
$$

where $C$ is a positive constant depending on $p, k$ and $n$.

Moreover, we have the following result based on Sobolev's lemma.

LEMma 2.3. (i) Let $m=N(\equiv[n / 2]+1)$ and let $u^{j}(j=1,2, \cdots, r)$ belong to $H^{m}$. If multi-indices $\nu^{j}(j=1,2, \cdots, r)$ satisfy $\sum_{j=1}^{r}\left|\nu^{j}\right| \leqq m$, then

$$
D_{x}^{\nu 1} u^{1} D_{x}^{\iota^{2}} u^{2} \cdots D_{x}^{\nu r} u^{r} \in L^{2} .
$$

In addition,

$$
\left\|D_{x}^{\nu 1} u^{1} D_{x}^{\nu 2} u^{2} \cdots D_{x}^{{ }^{r}} u^{r}\right\| \leqq C \sum_{j=1}^{r}\left\|u^{j}\right\|_{m},
$$

where $C$ is a positive constant depending on $n, \nu^{1}, \nu^{2}, \cdots, \nu^{r}$.

(ii) Let $m \geqq N+1$ and let $u^{1} \in H^{m}, u^{j} \in H^{m-1}(j=2,3, \cdots, r)$. If multi-indices $\nu^{j}(j=1,2, \cdots, r)$ satisfy $\left|\nu^{1}\right| \geqq\left|\nu^{j}\right|(j=2,3, \cdots, r)$ and $\sum_{j=1}^{r}\left|\nu^{j}\right|$ $\leqq m$, then

$$
D_{x}^{\nu 1} u^{1} D_{x}^{\nu 2} u^{2} \cdots D_{x}^{\nu r} u^{r} \in L^{2}
$$


In addition,

$$
\left\|D_{x}^{\nu 1} u^{1} D_{x}^{\nu 2} u^{2} \cdots D_{x}^{\nu r} u^{r}\right\| \leqq C\left\|u^{1}\right\|_{m} \prod_{j=2}^{r}\left\|u^{j}\right\|_{m-1},
$$

where $C$ is a positive constant depending on $m, n, \nu^{1}, \nu^{2}, \cdots, \nu^{r}$.

Proof. For the proof of this lemma, see e.g. Mizohata [14, Chapt. 7]. [q.e.d.]

Now we are in a position to show the next fundamental lemma which will be of frequent use. For convenience, put

$$
M_{k}(\rho)=\sup \left\{\left|D_{\eta}^{\alpha} a_{i \jmath}(\eta)\right| ; 1 \leqq i, j \leqq n,|\alpha| \leqq k, \text { for } \eta \in R^{n} \text { with }|\eta| \leqq \rho\right\}
$$

and denote by $C(a, b, \cdots)$ various positive constants depending on $a, b, \cdots$.

Lemma 2.4. Suppose that (A.1) holds.

(i) Let $u, v \in H^{m+2}$. Then

$$
\begin{aligned}
& \left\|a_{i \jmath}(\operatorname{grad} u) u_{i j}-a_{i \jmath}(\operatorname{grad} v) v_{i \jmath}\right\|_{m} \\
& \leq C(m, n)\left\{M_{m}\left(\|\operatorname{grad} u\|_{\infty}\right)\left(1+\|\operatorname{grad} u\|_{m}^{m}\right)\|\Delta(u-v)\|_{m}\right. \\
& +M_{m+1}\left(\|\operatorname{grad} u\|_{\infty}+\|\operatorname{grad} v\|_{\infty}\right)\left(1+\|\operatorname{grad} u\|_{m}^{m}+\|\operatorname{grad} v\|_{m}^{m}\right) \\
& \left.\times\|\Delta v\|_{m}\|\operatorname{grad}(u-v)\|_{m}\right\},
\end{aligned}
$$

for every $1 \leqq i, j \leqq n$.

(ii) Let $u \in H^{m+2}$ and let $|\alpha| \leqq m$. Then

$$
\begin{aligned}
& \left\|D_{x}^{\alpha}\left\{a_{i j}(\operatorname{grad} u) u_{i j}\right\}-a_{i \jmath}(\operatorname{grad} u) D_{x}^{\alpha} u_{i \jmath}\right\|_{1} \\
& \quad \leqq C(\alpha, n) M_{|\alpha|+1}\left(\|\operatorname{grad} u\|_{\infty}\right)\left(1+\|\operatorname{grad} u\|_{N(\alpha)}^{|\alpha|}\right)\|\Delta u\|_{N(\alpha)}^{2},
\end{aligned}
$$

for $1 \leqq i, j \leqq n$, where $N(\alpha)=\max \{|\alpha|, N\}$.

(iii) Let $u, v \in H^{m+2}$ and let $|\alpha| \leqq m$. Then

$$
\begin{aligned}
\left\|D_{x}^{\alpha}\left\{a_{i j}(\operatorname{grad} u) v_{i j}\right\}-a_{i j}(\operatorname{grad} u) D_{x}^{\alpha} v_{i j}\right\| & \\
\leqq C(\alpha, n) M_{|\alpha|}\left(\|\operatorname{grad} u\|_{\infty}\right)(1+ & \left.\|\operatorname{grad} u\|_{N(\alpha)}^{|\alpha|-1}\right) \\
& \times\|\Delta u\|_{N(\alpha)}\|\operatorname{grad} v\|_{N(\alpha)},
\end{aligned}
$$

for $1 \leqq i, j \leqq n$, where $N(\alpha)=\max \{|\alpha|, N\}$.

Proof. (i) Let $u, v \in H^{m+2}$. Decomposing $a_{i j}(\operatorname{grad} u) u_{i j}-a_{i j}(\operatorname{grad} v) v_{i j}$ as

$$
a_{i \jmath}(\operatorname{grad} u)\left(u_{i j}-v_{i \jmath}\right)+\left\{a_{i \jmath}(\operatorname{grad} u)-a_{i j}(\operatorname{grad} v)\right\} v_{i \jmath} \equiv I_{1}(u, v)+I_{2}(u, v),
$$

we shall estimate each $I_{i}(u, v), i=1,2$. 
By Leibnitz' formula,

$$
D_{x}^{\alpha} I_{1}(u, v)=\sum_{\beta \leqq \alpha}\left(\begin{array}{c}
\alpha \\
\beta
\end{array}\right) D_{x}^{\beta}\left\{a_{i j}(\operatorname{grad} u)\right\} D_{x}^{\alpha-\beta}\left(u_{i j}-v_{i j}\right)
$$

where $\alpha=\left(\alpha_{1}, \alpha_{2}, \cdots, \alpha_{n}\right), \beta=\left(\beta_{1}, \beta_{2}, \cdots, \beta_{n}\right)$,

$$
\left(\begin{array}{l}
\alpha \\
\beta
\end{array}\right)=\frac{\alpha_{1} ! \cdots \alpha_{n} !}{\left(\alpha_{1}-\beta_{1}\right) ! \cdots\left(\alpha_{n}-\beta_{n}\right) ! \beta_{1} ! \cdots \beta_{n} !},
$$

and $\beta \leqq \alpha$ means $\beta_{j} \leqq \alpha_{j}$ for every $1 \leqq j \leqq n$. From the chain rule of a composite function, it becomes that $D_{x}^{\beta}\left\{a_{i j}(\operatorname{grad} u)\right\}$ is expressed as a linear combination of functions of the form

$$
\left(D_{\eta}^{r} a_{i j}\right)(\operatorname{grad} u) \prod_{p=1}^{q} D_{x}^{\beta^{p}} u_{k_{p}}, \quad u_{k_{p}}=\partial u / \partial x_{k_{p}},
$$

where $|\gamma| \leqq|\beta|, q \leqq|\beta|$ and $|\beta|=\sum_{p=1}^{q}\left|\beta^{p}\right|$. Since $u \in H^{m+2}(m \geqq N)$ and $|\alpha-\beta|+\sum_{p=1}^{q}\left|\beta^{p}\right|=|\alpha|$, it is possible to show with the use of Lemma 2.3 that

$$
\left\|D_{x}^{\alpha} I_{1}(u, v)\right\| \leqq C(\alpha, n) M_{|\alpha|}\left(\|\operatorname{grad} u\|_{\infty}\right)\left(1+\|\operatorname{grad} u\|_{N(\alpha)}^{|\alpha|}\right)\|\Delta(u-v)\|_{N(\alpha)},
$$

with $N(\alpha)=\max \{|\alpha|, N\}$, where we have used the following inequalities: for any $s \geqq 0$,

$$
\left\|u_{i}\right\|_{s} \leqq\|\operatorname{grad} u\|_{s}, \quad 1 \leqq i \leqq n
$$

and

$$
\left\|u_{i \jmath}\right\|_{s} \leqq\|\Delta u\|_{s}, \quad 1 \leqq i, j \leqq n .
$$

(These inequalities can be derived from Plancherel' theorem

$$
\left.\left\|D_{x}^{\alpha} u\right\|=\left\|\xi^{\alpha} \hat{u}\right\| .\right)
$$

Hence it follows from (2.4) with $|\alpha| \leqq m$ that

$$
\left\|I_{1}(u, v)\right\|_{m} \leqq C(m, n) M_{m}\left(\|\operatorname{grad} u\|_{\infty}\right)\left(1+\|\operatorname{grad} u\|_{m}^{m}\right)\|\Delta(u-v)\|_{m} .
$$

To estimate $I_{2}(u, v)$, we note

$$
\begin{aligned}
& a_{i j}(\operatorname{grad} u)-a_{i j}(\operatorname{grad} v) \\
& \quad=\sum_{k=1}^{n} \int_{0}^{1} \frac{\partial a_{i j}}{\partial \eta_{k}}(\theta \operatorname{grad} u+(1-\theta) \operatorname{grad} v) d \theta\left(u_{k}-v_{k}\right) .
\end{aligned}
$$

Therefore, for $|\alpha| \leqq m$, 


$$
\begin{aligned}
D_{x}^{\alpha} I_{2}(u, v)= & \sum_{\beta \leq \alpha}\left(\begin{array}{c}
\alpha \\
\beta
\end{array}\right) D_{x}^{\beta}\left\{a_{i j}(\operatorname{grad} u)-a_{i j}(\operatorname{grad} v)\right\} D_{x}^{\alpha-\beta} v_{i j} \\
= & \sum_{\substack{\beta \leq \alpha \\
\gamma \leq \beta}} \sum_{k=1}^{n}\left(\begin{array}{c}
\alpha \\
\beta
\end{array}\right)\left(\begin{array}{c}
\beta \\
\gamma
\end{array}\right) \int_{0}^{1} D_{x}^{r}\left\{\frac{\partial a_{i j}}{\partial \eta_{k}}(\theta \operatorname{grad} u+(1-\theta) \operatorname{grad} v)\right\} d \theta \\
& \times D_{x}^{\beta-r}\left(u_{k}-v_{k}\right) D_{x}^{\alpha-\beta} v_{i j} .
\end{aligned}
$$

Since $D_{x}^{r}\left\{\partial a_{i j} / \partial \eta_{k}(\theta \operatorname{grad} u+(1-\theta) \operatorname{grad} v)\right\}$ is expressed as a linear combination of functions of the form

$$
\left(D_{\eta}^{\delta} a_{i j}\right)(\theta \operatorname{grad} u+(1-\theta) \operatorname{grad} v) \prod_{p=1}^{q} D_{x}^{\tau^{p}}\left(\theta u_{k_{p}}+(1-\theta) v_{k_{p}}\right),
$$

where $|\delta| \leqq|\gamma|+1, q \leqq|\gamma|$ and $|\gamma|=\sum_{p=1}^{q}\left|\gamma^{p}\right|$, it follows from Lemma 2.3 that

$$
\begin{aligned}
\left\|D_{x}^{\alpha} I_{2}(u, v)\right\| \leqq & C(\alpha, n) M_{|\alpha|+1}\left(\|\operatorname{grad} u\|_{\infty}+\|\operatorname{grad} v\|_{\infty}\right)\|\Delta v\|_{N(\alpha)} \\
& \times\left(1+\|\operatorname{grad} u\|_{N(\alpha)}^{|\alpha|}+\|\operatorname{grad} v\|_{N(\alpha)}^{|\alpha|}\right)\|\operatorname{grad}(u-v)\|_{N(\alpha)},
\end{aligned}
$$

with $N(\alpha)=\max \{|\alpha|, N\}$. Since (2.6) with $|\alpha| \leqq m$ yields

$$
\begin{aligned}
\left\|I_{2}(u, v)\right\|_{m} \leqq & C(m, n) M_{m+1}\left(\|\operatorname{grad} u\|_{\infty}+\|\operatorname{grad} v\|_{\infty}\right)\|\Delta v\|_{m} \\
& \times\left(1+\|\operatorname{grad} u\|_{m}^{m}+\|\operatorname{grad} v\|_{m}^{m}\right)\|\operatorname{grad}(u-v)\|_{m},
\end{aligned}
$$

we obtain (2.1) by combining (2.5) and (2.7).

(ii) Let $u \in H^{m+2}$ and $|\alpha| \leqq m$. By Leibnitz' formula

$$
\begin{aligned}
& D_{x}^{\alpha}\left\{a_{i j}(\operatorname{grad} u) u_{i j}\right\}-a_{i j}(\operatorname{grad} u) D_{x}^{\alpha} u_{i j} \\
& \quad=\sum_{0<\beta \leqq \alpha}\left(\begin{array}{c}
\alpha \\
\beta
\end{array}\right) D_{x}^{\beta}\left\{a_{i j}(\operatorname{grad} u)\right\} D_{x}^{\alpha-\beta} u_{i j},
\end{aligned}
$$

where $\beta>0$ means that $\beta_{k} \geqq 1$ for some $k$. For convenience, set $D_{x}^{1(k)}=$ $\partial / \partial x_{k}$. Then, for some $1 \leqq k \leqq n$,

$$
\begin{aligned}
D_{x}^{\beta}\left\{a_{i j}(\operatorname{grad} u)\right\} & =D_{x}^{\beta-1(k)}\left\{\sum_{\ell=1}^{n} \frac{\partial a_{i j}}{\partial \eta_{\ell}}(\operatorname{grad} u) u_{k \ell}\right\} \\
& =\sum_{\ell=1}^{n} \sum_{\gamma \leqq \beta-1(k)}\left(\begin{array}{c}
\beta-1(k) \\
\gamma
\end{array}\right) D_{x}^{r}\left\{\frac{\partial a_{i j}}{\partial \eta_{\ell}}(\operatorname{grad} u)\right\} D_{x}^{\beta-1(k)-r} u_{k \ell} .
\end{aligned}
$$

Hence, as in (i), (2.8) is expressed as a linear combination of functions of the form

$$
\left(D_{\eta}^{\delta} a_{i j}\right)(\operatorname{grad} u) \prod_{p=1}^{q} D_{x}^{r^{p}} u_{k_{p}} D_{x}^{\beta-1(k)-r} u_{k \ell} D_{x}^{\alpha-\beta} u_{i j},
$$

where $1 \leqq|\beta| \leqq|\alpha|,|\gamma| \leqq|\beta|-1,|\delta| \leqq|\gamma|+1, q \leqq|\gamma|$ and $|\gamma|=\sum_{p=1}^{q}\left|\gamma^{p}\right|$. 
Consequently, applying Lemma 2.3 we can deduce

$$
\begin{aligned}
& \left\|D_{x}^{\alpha}\left\{a_{i j}(\operatorname{grad} u) u_{i j}\right\}-a_{i j}(\operatorname{grad} u) D_{x}^{\alpha} u_{i j}\right\|_{1} \\
& \quad=\left[\sum_{\left|\alpha^{\prime}\right| \leqq 1} \| D_{x}^{\alpha^{\prime}}\left\{D_{x}^{\alpha}\left(a_{i j}(\operatorname{grad} u) u_{i j}-a_{i j}(\operatorname{grad} u) D_{x}^{\alpha} u_{i j}\right\} \|^{2}\right]^{1 / 2}\right. \\
& \quad \leqq C(\alpha, n) M_{|\alpha|+1}\left(\|\operatorname{grad} u\|_{\infty}\right)\left(1+\|\operatorname{grad} u\|_{N(\alpha)}^{|\alpha|}\right)\|\Delta u\|_{N(\alpha)}^{2},
\end{aligned}
$$

which is the desired inequality (2.2).

(iii) Let $u, v \in H^{m+2}$ and let $|\alpha| \leqq m$. As in the proof of (2.2), it is seen that $D_{x}^{\alpha}\left\{a_{i j}(\operatorname{grad} u) v_{i j}\right\}-a_{i j}(\operatorname{grad} u) D_{x}^{\alpha} v_{i j}$ is expressed as a linear combination of functions of the form

$$
\left(D_{\eta}^{\delta} a_{i j}\right)(\operatorname{grad} u) \prod_{p=1}^{q} D_{x}^{\gamma^{p}} u_{k_{p}} D_{x}^{\beta-1(k)-\gamma} u_{k \ell} D_{x}^{\alpha-\beta+1(i)} v_{j},
$$

where $1 \leqq|\beta| \leqq|\alpha|,|\gamma| \leqq|\beta|-1,|\delta| \leqq|\gamma|+1, q \leqq|\gamma|$ and $|\gamma|=\sum_{p=1}^{q}\left|\gamma^{p}\right|$. Hence (2.3) follows with the use of Lemma 2.3.

[q.e.d.]

\section{§3. Abstract formulation}

In this section we shall formulate the initial value problem (1.1)-(1.3) to an abstract initial value problem in the Sobolev space $H^{m}$ with $m \geqq$ $N(\equiv[n / 2]+1)$.

We first define a closed linear operator $A$ with dense domain $D(A)$ in $H^{m}$ by

$$
\left\{\begin{array}{l}
D(A)=H^{m+2} \\
A u=(\Delta-1) u \quad \text { for } u \in D(A) .
\end{array}\right.
$$

It is easy to see that $A$ is a negative self-adjoint operator in $H^{m}$. Therefore, $A$ generates an analytic semi-group of bounded linear operators $T(t)$, $t \geqq 0$, on $H^{m}$. Moreover, it follows with the aid of Plancherel's theorem that

$$
\|T(t) u\|_{m} \leqq\|u\|_{m} \quad \text { for } u \in H^{m} .
$$

The original problem (1.1)-(1.3) can be written as

$$
\begin{aligned}
& u_{t t}-\lambda A u_{t}-B(u)+(c-\lambda) u_{t}=f, \quad t \geqq 0, \\
& u(0)=u_{0}, \\
& u_{t}(0)=v_{0},
\end{aligned}
$$

where $B(u)=\sum_{i, j=1}^{n} a_{i j}(\operatorname{grad} u) u_{i j}$. By Lemma 2.4 (i), $B(u)$ has the following property: 


$$
\begin{aligned}
\|B(u)-B(v)\|_{m} \leqq & C(m, n)\left\{M_{m}\left(\|\operatorname{grad} u\|_{\infty}\right)\left(1+\|\operatorname{grad} u\|_{m}^{m}\right)\|\Delta(u-v)\|_{m}\right. \\
& +M_{m+1}\left(\|\operatorname{grad} u\|_{\infty}+\|\operatorname{grad} v\|_{\infty}\right)\|\Delta v\|_{m} \\
& \left.\times\left(1+\|\operatorname{grad} u\|_{m}^{m}+\|\operatorname{grad} v\|_{m}^{m}\right)\|\operatorname{grad}(u-v)\|_{m}\right\}, \\
& \text { for } u, v \in D(A),
\end{aligned}
$$

where $C(m, n)$ is a positive constant depending on $m$ and $n$.

Let $T>0$ be fixed. Assuming $u_{0} \in H^{m+2}, v_{0} \in H^{m}$ and $f \in C^{1}\left([0, T] ; H^{m}\right)$, we intend to seek a solution $u$ of (3.3)-(3.5) within the class

$$
u \in C\left([0, T] ; H^{m+2}\right) \cap C^{1}\left([0, T] ; H^{m}\right) \cap C^{1}\left((0, T] ; H^{m+2}\right) \cap C^{2}\left((0, T] ; H^{m}\right) .
$$

For this purpose, we shall reduce second-order equation (3.3) to a system of first-order equations (cf. Krein [9, Chap. 3] and Yamada [21]). Introduce two unknown functions $v$ and $w$ by

$$
v=u_{t} \quad \text { and } \quad w=A u .
$$

Since $A$ is closed and it has a bounded inverse $A^{-1}$ (recall definition (3.1)), equation (3.3) is rewritten in the form

$$
\left\{\begin{array}{l}
v_{t}(t)=\lambda A v(t)+B\left(A^{-1} w(t)\right)+(\lambda-c) v(t)+f(t), \\
w_{t}(t)=A v(t)
\end{array}\right.
$$

System (3.9) may be regarded as a single equation in the product space $H^{m} \times H^{m}$ :

$$
U_{t}(t)=A U(t)+B(U(t))+F(t)
$$

where

$$
U=\left(\begin{array}{c}
v \\
w
\end{array}\right), \quad A=\left(\begin{array}{cc}
\lambda A & 0 \\
A & 0
\end{array}\right), \quad \boldsymbol{B}(U)=\left(\begin{array}{c}
B\left(A^{-1} w\right)+(\lambda-c) v \\
0
\end{array}\right), \quad F=\left(\begin{array}{l}
f \\
0
\end{array}\right) .
$$

Thus the original initial value problem (3.3)-(3.5) is reduced to another initial value problem for (3.10) with the initial condition

$$
U(0)=U_{0} \equiv{ }^{t}\left(v_{0}, A u_{0}\right) .
$$

Furthermore, it is easy to verify

$$
U \in C\left([0, T] ; H^{m} \times H^{m}\right) \cap C^{1}\left((0, T] ; H^{m} \times H^{m}\right),
$$

if $u$ is a solution of (3.3)-(3.5) in the class (3.7).

Conversely, let $U$ be a solution of (3.10), (3.11) satisfying (3.12). Then 


$$
u(t)=u_{0}+\int_{0}^{t} v(s) d s
$$

will be a solution of (3.3)-(3.5). In fact, we have

Proposition 3.1. Let $u_{0} \in H^{m+2}, v_{0} \in H^{m}$ and $f \in C^{1}\left([0, T] ; H^{m}\right)$. If $u$ is a function satisfying (3.3), (3.4), (3.5) and (3.7), then $U={ }^{t}(v, w)$ defined by (3.8) satisfies (3.10), (3.11) and (3.12).

Conversely, if $U={ }^{t}(v, w)$ is a function satisfying (3.10), (3.11) and (3.12), then $u$ defined by (3.13) satisfies (3.3), (3.4), (3.5) and (3.7).

Proof. The first part is evident from the preceding consideration.

We shall prove the latter half. Let $U$ be a function satisfying (3.10)(3.12) and define $u$ by (3.13). Since $v \in C\left([0, T] ; H^{m}\right) \cap C^{1}\left((0, T] ; H^{m}\right)$, it becomes easily that $u$ belongs to $C^{1}\left([0, T] ; H^{m}\right) \cap C^{2}\left((0, T] ; H^{m}\right)$ and that it satisfies

$$
u_{t t}(t)=\lambda A u_{t}(t)+B\left(A^{-1} w(t)\right)+(\lambda-c) u_{t}(t)+f(t),
$$

on (0,T]. Moreover, $w_{t}=A u_{t} \in C\left((0, T] ; H^{m}\right)$ implies $u \in C^{1}\left((0, T] ; H^{m+2}\right)$.

On the other hand, note

$$
u(t)-u(\varepsilon)=\int_{\varepsilon}^{t} u_{t}(s) d s=\int_{\varepsilon}^{t} v(s) d s
$$

for any $0<\varepsilon<T$. Hence, since $A$ is closed, we have

$$
A u(t)-A u(\varepsilon)=\int_{s}^{t} A v(s) d s=\int_{\varepsilon}^{t} w_{t}(s) d s=w(t)-w(\varepsilon),
$$

from which, by letting $\varepsilon \downarrow 0$, it follows that

$$
A u(t)=w(t) \quad \text { on }[0, T] .
$$

Since $w \in C\left([0, T] ; H^{m}\right)$, (3.15) implies $u \in C\left([0, T] ; H^{m+2}\right) . \quad$ By (3.14) and (3.15), it is easy to verify (3.3). Thus we complete the proof. [q.e.d.]

Proposition 3.1 assures the equivalence between initial value problem (3.3)-(3.5) within class (3.7) and initial value problem (3.10), (3.11) within class (3.12). So we may deal with (3.10), (3.11) to solve (3.3)-(3.5).

It is easily verified that $A$ is a closed linear operator with dense domain $D(A)=H^{m+2} \times H^{m}$ (in $H^{m} \times H^{m}$ ). Moreover, $A$ also generates an analytic semi-group of bounded linear operators $T(t), t \geqq 0$, on $H^{m} \times H^{m}$;

$$
T(t)=\left(\begin{array}{ll}
T(\lambda t) & 0 \\
\{T(\lambda t)-I\} / \lambda & I
\end{array}\right), \quad I=\text { identity operator }
$$


where $T(t)$ is the analytic semi-group generated by $A$. It is convenient to provide the product space $H^{m} \times H^{m}$ with the following norm

$$
\|U\|_{m}=\|v\|_{m}+\|w\|_{m}, \quad U={ }^{t}(v, w) .
$$

Then it follows from (3.2) that

$$
\begin{aligned}
\|T(t) U\|_{m} & =\|T(\lambda t) v\|_{m}+\left\|\lambda^{-1}\{T(\lambda t)-I\} v+w\right\|_{m} \\
& \leqq\left(1+\frac{2}{\lambda}\right)\|v\|_{m}+\|w\|_{m} \leqq\left(1+\frac{2}{\lambda}\right)\|U\|_{m}
\end{aligned}
$$

for $U={ }^{t}(v, w) \in H^{m} \times H^{m}$. Let $s_{0}$ be a positive constant such that

$$
\|u\|_{\infty} \leqq s_{0}\|u\|_{N} \quad \text { for } u \in H^{N} \text {; }
$$

the existence of such $s_{0}$ is assured by Lemma 2.2 (i). Then, as to the nonlinear operator $\boldsymbol{B}(U)$, we have from (3.6)

$$
\begin{aligned}
& \left\|\boldsymbol{B}\left(U^{1}\right)-\boldsymbol{B}\left(U^{2}\right)\right\|_{m} \leqq\left\|B\left(A^{-1} w^{1}\right)-B\left(A^{-1} w^{2}\right)\right\|_{m}+|\lambda-c|\left\|v^{1}-v^{2}\right\|_{m} \\
& \leqq C(m, n)\left\{M_{m}\left(s_{0}\left\|w^{1}\right\|_{N}\right)\left(1+\left\|w^{1}\right\|_{m-1}^{m}\right)\left\|w^{1}-w^{2}\right\|_{m}\right. \\
& +M_{m+1}\left(s_{0}\left(\left\|w^{1}\right\|_{N}+\left\|w^{2}\right\|_{N}\right)\right)\left(1+\left\|w^{1}\right\|_{m-1}^{m}+\left\|w^{2}\right\|_{m-1}^{m}\right) \\
& \left.\times\left\|w^{2}\right\|_{m}\left\|w^{1}-w^{2}\right\|_{m-1}\right\}+|\lambda-c|\left\|v^{1}-v^{2}\right\|_{m} \text {, } \\
& \text { for } U^{i}={ }^{t}\left(v^{i}, w^{i}\right), \quad i=1,2 \text {, }
\end{aligned}
$$

where we have used Plancherel's theorem. Hence, (3.10) can be regarded as an abstract semilinear evolution equation of parabolic type. It is well known that, if $U$ is a solution of (3.10), (3.11), then it satisfies the next integral equation

$$
U(t)=T(t) U_{0}+\int_{0}^{t} T(t-s)\{\boldsymbol{B}(U(s))+F(s)\} d s, \quad 0 \leqq t \leqq T .
$$

(see e.g. Krein [9]). Furthermore, we have

Proposition 3.2. Let $u_{0} \in H^{m+2}, v_{0} \in H^{m}$ and $f \in C^{1}\left([0, T] ; H^{m}\right)$. If $U$ $\in C\left([0, T] ; H^{m} \times H^{m}\right)$ satisfies (3.19) with $U_{0}={ }^{t}\left(v_{0}, A u_{0}\right)$, then $U$ is a solution of (3.10), (3.11) within class (3.12).

Proof. Let $U \in C\left([0, T] ; H^{m} \times H^{m}\right)$ satisfy integral equation (3.19). Then the function $t \rightarrow B(U(t))$ is strongly continuous in $H^{m} \times H^{m}$ by (3.18), so that it is bounded in $H^{m} \times H^{m}$. Hence it follows by virtue of Pazy's result [17, Lemma 5.1] that the function

$$
t \longrightarrow \int_{0}^{t} T(t-s)\{B(U(s))+F(s)\} d s
$$


is strongly Hölder continuous on $[0, T]$ with exponent $0<\theta<1$ in $H^{m} \times$ $H^{m}$. Since $T(t)$ is the analytic semi-group, $U$ is also strongly Hölder continuous on $(0, T]$ with exponent $0<\theta<1$. Therefore, the local Lipschitz continuity of $U \rightarrow \boldsymbol{B}(U)$ (see (3.18)) implies that the function $t \rightarrow \boldsymbol{B}(U(t)$ ) is, indeed, strongly Hölder continuous on $(0, T]$. Hence it follows from the well known result in the theory of evolution equations of parabolic type (see e.g. Krein [9, Chap. $1 \S 6]$ ) that $U$ is strongly continuously differentiable on $(0, T]$, i.e., $U \in C^{1}\left((0, T] ; H^{m} \times H^{m}\right)$, and that $U$ satisfies equation (3.10) on $(0, T]$. Since $U$ clearly satisfies $U(0)=U_{0}$, the proof is complete.

[q.e.d.]

Remark 3.1. Suppose $v_{0} \in H^{m+2}$ in Proposition 3.2. Since $U_{0}={ }^{t}\left(v_{0}, A u_{0}\right)$ $\in H^{m+2} \times H^{m}=D(A)$, it is possible to show $U \in C^{1}\left([0, T] ; H^{m} \times H^{m}\right)$. In this case, $u$ defined by (3.13) belongs to the class $C^{1}\left([0, T] ; H^{m+2}\right) \cap$ $C^{2}\left([0, T] ; H^{m}\right)$.

Remark 3.2. The abstract formulation developed in this section has been employed by the author [21] to treat the mixed problem for the special case $n=1$ with zero Dirichlet condition. (The existence result in [21] is slightly better than that of Greenberg, MacCamy and Mizel [7]).

By Propositions 3.1 and 3.2, it suffices to find a strongly continuous solution $U$ of (3.19) in order to solve (3.3)-(3.5) in the class (3.7). In the next section, we shall show the existence of a solution of (3.19).

\section{§4. Proofs of existence theorems}

\subsection{Proof of Theorem I}

We first assume $u_{0} \in H^{m+2}, v_{0} \in H^{m}$ and $f \in C^{1}\left([0, \infty) ; H^{m}\right)$. From the results in the preceding section, we have only to consider integral equation (3.19) in order to treat initial value problem (3.3)-(3.5).

Define a set

$$
\begin{array}{r}
K=\left\{U={ }^{t}(v, w) \in C\left([0, \tau] ; H^{m} \times H^{m}\right) ; U(0)=U_{0} \equiv{ }^{t}\left(v_{0}, A u_{0}\right),\right. \\
\text { and } \left.\|U(t)\|_{m} \leqq L \text { on }[0, \tau]\right\},
\end{array}
$$

where positive constants $L$ and $\tau$ will be determined later. Clearly, the set $K$ is closed in a Banach space $C\left([0, \tau] ; H^{m} \times H^{m}\right)$ equipped with the norm

$$
\mid\|U\|=\sup _{0 \leqq t \leqq \tau}\|U(t)\|_{m}
$$


For each $\hat{U} \in K$, define a mapping $U=S \hat{U}$ by

$$
U(t)=\boldsymbol{T}(t) U_{0}+\int_{0}^{t} T(t-s)\{\boldsymbol{B}(\hat{U}(s))+F(s)\} d s, \quad 0 \leqq t \leqq \tau .
$$

(By (3.18), $S$ maps $K$ into $C\left([0, \tau] ; H^{m} \times H^{m}\right)$ ). We shall take suitable $L$ and $\tau$ so that $S$ becomes a strictly contraction mapping from $K$ into itself.

By virtue of (3.16), (3.17) and (3.18) (with $U^{2}=0$ ), it follows from (4.2) that

$$
\begin{aligned}
\|U(t)\|_{m} & \leqq\left(1+\frac{2}{\lambda}\right)\left\{\left\|U_{0}\right\|_{m}+\int_{0}^{t}\left(\|\boldsymbol{B}(\hat{U}(s))\|_{m}+\|F(s)\|_{m}\right) d s\right\} \\
\leqq & \left(1+\frac{2}{\lambda}\right)\left[\left\|U_{0}\right\|_{m}+\left\{C(m, n) M_{m}\left(s_{0} L\right)\left(1+L^{m}\right) L+|\lambda-c| L\right\} t\right. \\
& \left.\quad+\int_{0}^{t}\|f(s)\|_{m} d s\right], \quad 0 \leqq t \leqq \tau
\end{aligned}
$$

We take a sufficiently large $L$ such that

$$
L>\left(1+\frac{2}{\lambda}\right)\left\|U_{0}\right\|_{m},
$$

and choose $\tau$ so small that

$$
\begin{aligned}
\left(1+\frac{2}{\lambda}\right)\left[\left\|U_{0}\right\|_{m}+\left\{C(m, n) M_{m}\left(s_{0} L\right)\left(1+L^{m}\right) L+|\lambda-c| L\right\} \tau\right. & \\
& \left.+\int_{0}^{\tau}\|f(s)\|_{m} d s\right] \leqq L
\end{aligned}
$$

may be true. Then it is easily seen from (4.3) and (4.5) that

$$
\|U(t)\|_{m} \leqq L \quad \text { for } 0 \leqq t \leqq \tau,
$$

which implies that $S$ maps $K$ into itself (recall definition (4.1)).

For each $\hat{U}^{i} \in K(i=1,2)$, set $U^{i}=S \hat{U}^{i}(i=1,2)$. Since

$$
U^{1}(t)-U^{2}(t)=\int_{0}^{t} T(t-s)\left\{B\left(\hat{U}^{1}(s)\right)-B\left(\hat{U}^{2}(s)\right)\right\} d s, \quad 0 \leqq t \leqq \tau,
$$

by (4.2), it follows with the use of (3.16) and (3.18) that

$$
\begin{gathered}
\left\|U^{1}(t)-U^{2}(t)\right\|_{m} \leqq\left(1+\frac{2}{\lambda}\right) \int_{0}^{t}\left\|\boldsymbol{B}\left(\hat{U}^{1}(s)\right)-\boldsymbol{B}\left(\hat{U}^{2}(s)\right)\right\|_{m} d s \\
\leqq\left(1+\frac{2}{\lambda}\right)\left[C ( m , n ) \left\{M_{m}\left(s_{0} L\right)\left(1+L^{m}\right)\right.\right.
\end{gathered}
$$




$$
\begin{aligned}
& \left.\left.+M_{m+1}\left(2 s_{0} L\right)\left(1+2 L^{m}\right) L\right\}+|\lambda-c|\right] \\
& \times \int_{0}^{t}\left\|\hat{U}^{1}(s)-\hat{U}^{2}(s)\right\|_{m} d s, \quad 0 \leqq t \leqq \tau .
\end{aligned}
$$

Therefore, making $\tau$ sufficiently small (if necessary) so that

$$
\begin{aligned}
\left(1+\frac{2}{\lambda}\right)\left[C(m, n)\left\{M_{m}\left(s_{0} L\right)\left(1+L^{m}\right)+M_{m+1}\left(2 s_{0} L\right)\left(1+2 L^{m}\right) L\right\}\right. & \\
& +|\lambda-c|] \tau<1,
\end{aligned}
$$

is satisfied, we see from (4.6) and (4.7) that $S: K \rightarrow K$ is a strictly contraction mapping. Consequently, $S$ has a unique fixed element $U \in K$. In other words, there exists a unique solution $U={ }^{t}(v, w) \in C\left([0, \tau] ; H^{m} \times H^{m}\right)$ of (3.19). Therefore, Propositions 3.1 and 3.2 assure that the function $u$ defined by (3.13) is a unique solution of (3.3)-(3.5) in the class (3.7). Thus the first part of Theorem $I$ is established.

Next assume $v_{0} \in H^{m+2}$. By Remark 3.1, the solution $u$ constructed above belongs to $C^{1}\left([0, \tau] ; H^{m+2}\right) \cap C^{2}\left([0, \tau] ; H^{m}\right)$.

Finally, it remains to prove $u \in C^{1}\left([0, \tau] ; H^{m+1}\right)$ if $v_{0} \in H^{m+1}$. To see this, take a sequence $\left\{v_{0}^{p}\right\}_{p=1}^{\infty} \subset H^{m+2}$ such that $v_{0}^{p} \rightarrow v_{0}$ in $H^{m+1}$ as $p \rightarrow \infty$.

We consider initial value problem (3.3)-(3.5) with initial value $v_{0}$ replaced by $v_{0}^{p}$. Let $u^{p}$ be the corresponding solution. Since the existence interval is determined by (4.4), (4.5) and (4.7), we may conclude that $u^{p}$ exists on $[0, \tau]$ (independent of $p$ ) and that it belongs to $C^{1}\left([0, \tau] ; H^{m+2}\right) \cap$ $C^{2}\left([0, \tau] ; H^{m}\right)$. Moreover, it follows from the preceding proof that there exists a positive constant $L$, independent of $p$, such that

$$
\left\|A u^{p}(t)\right\|_{m} \leqq L \text { and }\left\|u_{t}^{p}(t)\right\|_{m} \leqq L \quad \text { on }[0, \tau]
$$

(see (4.1) and (4.4)).

Set $U^{p}(t)={ }^{t}\left(u_{t}^{p}(t), A u^{p}(t)\right)$. Since $U^{p}$ satisfies the integral equation (3.19) with $U_{0}=U_{0}^{p} \equiv{ }^{t}\left(v_{0}^{p}, A u_{0}^{p}\right)$, we have

$$
U^{p}(t)-U^{q}(t)=\boldsymbol{T}(t)\left(U_{0}^{p}-U_{0}^{q}\right)+\int_{0}^{t} \boldsymbol{T}(t-s)\left\{\boldsymbol{B}\left(U^{p}(s)\right)-\boldsymbol{B}\left(U^{q}(s)\right)\right\} d s
$$

for $0 \leqq t \leqq \tau$. Hence making use of (3.16), (3.18) and (4.8) we get

$$
\begin{aligned}
\left\|U^{p}(t)-U^{q}(t)\right\|_{m} \leqq\left(1+\frac{2}{\lambda}\right)\left\{\| U_{0}^{p}\right. & -U_{0}^{q} \|_{m} \\
& \left.+M \int_{0}^{t}\left\|U^{p}(s)-U^{q}(s)\right\|_{m} d s\right\},
\end{aligned}
$$


with some $M>0$. Application of Gronwall's inequality to (4.9) yields

$$
\begin{array}{r}
\left\|U^{p}(t)-U^{q}(t)\right\|_{m} \leqq\left(1+\frac{2}{\lambda}\right) \exp \left\{\left(1+\frac{2}{\lambda}\right) M t\right\}\left\|U_{0}^{p}-U_{0}^{q}\right\|_{m}, \\
0 \leqq t \leqq \tau,
\end{array}
$$

which implies that both $\left\{u_{t}^{p}\right\}$ and $\left\{A u^{p}\right\}$ are Cauchy sequences in $C\left([0, \tau] ; H^{m}\right)$. Consequently, by the uniqueness of solutions, $u^{p}$ converges to $u$ in $C([0, \tau]$; $\left.H^{m+2}\right) \cap C^{1}\left([0, \tau] ; H^{m}\right)$ as $p \rightarrow \infty$.

Moreover, we shall show that $u^{p}$ converges to $u$ in $C^{1}\left([0, \tau] ; H^{m+1}\right)$. Note the next identity:

$$
\begin{aligned}
& D_{x}^{\alpha}\left(u_{t t}^{p}-u_{t t}^{q}\right)-\lambda D_{x}^{\alpha} \Delta\left(u_{t}^{p}-u_{t}^{q}\right)-D_{x}^{\alpha}\left\{B\left(u^{p}\right)-B\left(u^{q}\right)\right\}+c D_{x}^{\alpha}\left(u_{t}^{p}-u_{t}^{q}\right) \\
& \quad=0
\end{aligned}
$$

where $\alpha$ is a multi-index such that $|\alpha| \leqq m$. Taking the $\left(L^{2}-\right)$ inner product of (4.10) with $-D_{x}^{\alpha} \Delta\left(u_{t}^{p}-u_{t}^{q}\right)$ gives

$$
\begin{aligned}
& \frac{1}{2} \frac{d}{d t}\left\|D_{x}^{\alpha} \operatorname{grad}\left(u_{t}^{p}-u_{t}^{q}\right)\right\|^{2}+\lambda\left\|D_{x}^{\alpha} \Delta\left(u_{t}^{p}-u_{t}^{q}\right)\right\|^{2} \\
& \quad \leqq\left\|D_{x}^{\alpha}\left\{B\left(u^{p}\right)-B\left(u^{q}\right)\right\}\right\|\left\|D_{x}^{\alpha} \Delta\left(u_{t}^{p}-u_{t}^{q}\right)\right\|+|c|\left\|D_{x}^{\alpha} \operatorname{grad}\left(u_{t}^{p}-u_{t}^{q}\right)\right\|^{2} .
\end{aligned}
$$

Adding (4.11) for $|\alpha| \leqq m$ and arranging the resulting expression, we obtain

$$
\begin{aligned}
& \frac{1}{2} \frac{d}{d t}\left\|\operatorname{grad}\left(u_{t}^{p}-u_{t}^{q}\right)\right\|_{m}^{2}+\frac{\lambda}{2}\left\|\Delta\left(u_{t}^{p}-u_{t}^{q}\right)\right\|_{m}^{2} \\
& \quad \leqq M_{1}\left(\left\|u^{p}-u^{q}\right\|_{m+2}^{2}+\left\|\operatorname{grad}\left(u_{t}^{p}-u_{t}^{q}\right)\right\|_{m}^{2}\right), \quad 0 \leqq t \leqq \tau,
\end{aligned}
$$

with some $M_{1}>0$, where we have used (3.6) and (4.8). Integration of (4.12) with respect to $t \in[0, \tau]$ leads to

$$
\begin{aligned}
& \left\|\operatorname{grad}\left(u_{t}^{p}(t)-u_{t}^{q}(t)\right)\right\|_{m}^{2} \leqq\left\|\operatorname{grad}\left(v_{0}^{p}-v_{0}^{q}\right)\right\|_{m}^{2} \\
& \quad+2 M_{1} \int_{0}^{t}\left(\left\|u^{p}(s)-u^{q}(s)\right\|_{m+2}^{2}+\left\|\operatorname{grad}\left(u_{t}^{p}(s)-u_{t}^{q}(s)\right)\right\|_{m}^{2}\right) d s .
\end{aligned}
$$

Since $u^{p}$ converges to $u$ in $C\left([0, \tau] ; H^{m+2}\right)$, application of Gronwall's inequality to (4.13) assures that $u_{t}^{p}$ converges to $u_{t}$ in $C\left([0, \tau] ; H^{m+1}\right)$. Hence, $u \in C^{1}\left([0, \tau] ; H^{m+1}\right)$, which completes the proof.

[q.e.d.]

Remark 4.1. The existence interval $[0, \tau]$ of a local solution $u$ of (3.3)(3.5) depends on $m, n, \lambda,|c|, D_{\eta}^{\alpha} \alpha_{i j}(|\alpha| \leqq m+1),\left\|u_{0}\right\|_{m+2},\left\|v_{0}\right\|_{m}$ and $\|f(t)\|_{m}$. See (4.4), (4.5) and (4.7).

Remark 4.2. Cleménts [1], Ebihara [4], [5] and Tsutsumi [19] has con- 
sidered the mixed problems for equations of type (1.1) with a strong dissipative term in a bounded domain. Their approach is based on the Galerkin's method, which is not applicable to our initial value problems.

\subsection{Proof of Theorem II}

Assume that $c$ is positive and that the data $\left(u_{0}, v_{0}, f\right)$ belong to $H^{m+2}$ $\times H^{m+1} \times\left\{C^{1}\left([0, \infty) ; H^{m}\right) \cap C\left([0, \infty) ; H^{m+1}\right)\right\}$. From Theorem I we already know the existence of a positive constant $\tau$ such that the initial value problem (1.1)-(1.3) has a unique solution $u$ on $[0, \tau]$ satisfying

$$
u \in C\left([0, \tau] ; H^{m+2}\right) \cap C^{1}\left([0, \tau], H^{m+1}\right) \cap C^{1}\left((0, \tau] ; H^{m+2}\right) \cap C^{2}\left((0, \tau] ; H^{m}\right) .
$$

We shall extend the existence interval $[0, \tau]$ to $[0, \infty)$. To see this, it is necessary and sufficient to show the existence of a solution of integral equation (3.19) on $[0, \infty)$. (Note Propositions 3.1 and 3.2.)

Let $U={ }^{t}\left(u_{t}, A u\right)$ be a solution of (3.19) on $[0, \tau]$. We extend this $U$ to the interval $\left[0, \tau+\tau^{\prime}\right]\left(\tau^{\prime}>0\right)$ by defining $U(t)=V(t)$ for $\tau \leqq t \leqq \tau+\tau^{\prime}$, where $V$ is a solution of

$$
V(t)=\boldsymbol{T}(t-\tau) U(\tau)+\int_{\tau}^{t} \boldsymbol{T}(t-s)\{\boldsymbol{B}(V(s))+F(s)\} d s .
$$

The existence of a solution $V$ of (4.14) on an interval $\left[\tau, \tau+\tau^{\prime}\right]$ with $\tau^{\prime}>$ 0 follows from Theorem I. Hence $U$ becomes actually a solution of (3.19) on $\left[0, \tau+\tau^{\prime}\right]$.

Let $\left[0, \tau_{\mathrm{max}}\right)$ be the maximum interval to which $U$ can be continued. Suppose that $\tau_{\max }<\infty$ and $\sup _{0 \leqq t<\tau_{\max }}\|U(t)\|_{m}<\infty$. Then we can show in the standard way that the solution $U$ can be continued to an interval $\left[0, \tau_{\max }+\tau^{\prime \prime}\right]$ with $\tau^{\prime \prime}>0$, which contradicts to the maximality of $\tau_{\max }$ (see e.g. Pazy [17]). Therefore, it suffices to obtain an a priori bound for $\|U(t)\|_{m}$ to show the global existence of a solution of (3.19). To this aim, we shall deduce some a priori bounds for $\|u(t)\|_{m+2}$ and $\left\|u_{t}(t)\right\|_{m+1}$, $u$ being a solution of (1.1)-(1.3). (Recall Propositions 3.1 and 3.2.)

Let $T$ be any fixed positive number and let $u$ be a solution of (1.1)(1.3) satisfying

$$
u \in C\left([0, T] ; H^{m+2}\right) \cap C^{1}\left([0, T] ; H^{m+1}\right) \cap C^{1}\left((0, T] ; H^{m+2}\right) \cap C^{2}\left((0, T] ; H^{m}\right) .
$$

Taking the $m$-inner product of (1.1) with $-\Delta u_{t}$ leads to the following

$$
\sum_{|\alpha| \leqq m}\left(D_{x}^{\alpha} u_{t t}, D_{x}^{\alpha}(-\Delta) u_{t}\right)+\lambda \sum_{|\alpha| \leqq m}\left(D_{x}^{\alpha} \Delta u_{t}, D_{x}^{\alpha} \Delta u_{t}\right)
$$




$$
\begin{aligned}
& +\sum_{|\alpha| \leqq m} \sum_{i, j=1}^{n}\left(a_{i j}(\operatorname{grad} u) D_{x}^{\alpha} u_{i j}, D_{x}^{\alpha} \Delta u_{t}\right) \\
& +\sum_{|\alpha| \leqq m} \sum_{i, j=1}^{n}\left(D_{x}^{\alpha}\left\{a_{i j}(\operatorname{grad} u) u_{i j}\right\}-a_{i j}(\operatorname{grad} u) D_{x}^{\alpha} u_{i j}, D_{x}^{\alpha} \Delta u_{t}\right) \\
& +c \sum_{|\alpha| \leqq m}\left(D_{x}^{\alpha} u_{t}, D_{x}^{\alpha}(-\Delta) u_{t}\right)+\sum_{|\alpha| \leqq m}\left(D_{x}^{\alpha} f, D_{x}^{\alpha} \Delta u_{t}\right) \\
& \equiv I_{1}+I_{2}+I_{3}+I_{4}+I_{5}+I_{6} \\
& =0, \quad 0 \leqq t \leqq T .
\end{aligned}
$$

It is easy to see

$$
\begin{aligned}
& I_{1}=\frac{1}{2} \frac{d}{d t}\left\|\operatorname{grad} u_{t}(t)\right\|_{m}^{2}, \\
& I_{2}=\lambda\left\|\Delta u_{t}(t)\right\|_{m}^{2} \\
& I_{5}=c\left\|\operatorname{grad} u_{t}(t)\right\|_{m}^{2}, \\
& I_{6}=-\left(\operatorname{grad} f(t), \operatorname{grad} u_{t}(t)\right)_{m} \geqq-\|\operatorname{grad} f(t)\|_{m}\left\|\operatorname{grad} u_{t}(t)\right\|_{m} .
\end{aligned}
$$

Since

$$
I_{4}=-\sum_{|\alpha| \leqq m} \sum_{i, j, k=1}^{n}\left(\frac{\partial}{\partial x_{k}}\left[D_{x}^{\alpha}\left\{a_{i j}(\operatorname{grad} u) u_{i j}\right\}-a_{i j}(\operatorname{grad} u) D_{x}^{\alpha} u_{i j}\right], D_{x}^{\alpha} u_{k t}\right),
$$

we get in view of Lemma 2.4 (ii),

$$
\begin{aligned}
I_{4} \geqq & -C(m, n) M_{m+1}\left(\|\operatorname{grad} u(t)\|_{\infty}\right)\left(1+\|\operatorname{grad} u(t)\|_{m}^{m}\right) \\
& \times\|\Delta u(t)\|_{m}^{2}\left\|\operatorname{grad} u_{t}(t)\right\|_{m},
\end{aligned}
$$

with $m \geqq N=[n / 2]+1$. Finally, note the following identity:

$$
\begin{aligned}
I_{3}= & \sum_{|\alpha| \leqq m} \sum_{i, j, k=1}^{n}\left(a_{i j}(\operatorname{grad} u) D_{x}^{\alpha} u_{i j}, D_{x}^{\alpha} u_{k k t}\right) \\
= & \sum_{|\alpha| \leqq m} \sum_{i, j, k=1}^{n}\left(a_{i j}(\operatorname{grad} u) D_{x}^{\alpha} u_{i k}, D_{x}^{\alpha} u_{j k t}\right) \\
& +\sum_{|\alpha| \leqq m} \sum_{i, j, k, \ell=1}^{n}\left(\frac{\partial a_{i j}}{\partial \eta_{\ell}}(\operatorname{grad} u)\left(u_{j \ell} D_{x}^{\alpha} u_{i k}-u_{k \ell} D_{x}^{\alpha} u_{i j}\right), D_{x}^{\alpha} u_{k t}\right),
\end{aligned}
$$

which is obtained by integrating by parts. Since $a_{i \jmath}=a_{j i}$ by (A.2), $I_{3}$ can be rewritten as

$$
\begin{aligned}
I_{3}= & \frac{1}{2} \frac{d}{d t} \sum_{|\alpha| \leqq m} \sum_{i, j, k=1}^{n}\left(a_{i j}(\operatorname{grad} u) D_{x}^{\alpha} u_{i k}, D_{x}^{\alpha} u_{j k}\right) \\
& -\frac{1}{2} \sum_{|\alpha| \leqq m} \sum_{i, j, k, \ell=1}^{n}\left(\frac{\partial a_{i j}}{\partial \eta_{\ell}}(\operatorname{grad} u) u_{\ell t} D_{x}^{\alpha} u_{i k}, D_{x}^{\alpha} u_{j k}\right) \\
& +\sum_{|\alpha| \leqq m} \sum_{i, j, k, \ell=1}^{n}\left(\frac{\partial a_{i j}}{\partial \eta_{\ell}}(\operatorname{grad} u)\left(u_{j \ell} D_{x}^{\alpha} u_{i k}-u_{k \ell} D_{x}^{\alpha} u_{i j}\right), D_{x}^{\alpha} u_{k t}\right) .
\end{aligned}
$$


Hence, by Lemma 2.2 (i) and Plancherel's theorem,

$$
\begin{aligned}
I_{3} \geqq & \frac{1}{2} \frac{d}{d t} \sum_{|\alpha| \leqq m} \sum_{i, j, k=1}^{n}\left(a_{i \jmath}(\operatorname{grad} u(t)) D_{x}^{\alpha} u_{i k}(t), D_{x}^{\alpha} u_{j k}(t)\right) \\
& -C(m, n) M_{1}\left(\|\operatorname{grad} u(t)\|_{\infty}\right)\left\{\left\|\operatorname{grad} u_{t}(t)\right\|_{N}\|\Delta u(t)\|_{m}^{2}\right. \\
& \left.+\|\Delta u(t)\|_{N}\|\Delta u(t)\|_{m}\left\|\operatorname{grad} u_{t}(t)\right\|_{m}\right\} .
\end{aligned}
$$

Therefore, adding (4.15)-(4.20) and integrating the resulting expression with respect to $t$, we can obtain

$$
\begin{gathered}
\frac{1}{2}\left\|\operatorname{grad} u_{t}(t)\right\|_{m}^{2}+\frac{1}{2} a_{0}\left(\|\operatorname{grad} u(t)\|_{\infty}\right)\|\Delta u(t)\|_{m}^{2} \\
+\lambda \int_{0}^{t}\left\|\Delta u_{t}(s)\right\|_{m}^{2} d s+c \int_{0}^{t}\left\|\operatorname{grad} u_{t}(s)\right\|_{m}^{2} d s \\
\leqq \\
\frac{1}{2}\left\|\operatorname{grad} v_{0}\right\|_{m}^{2}+\frac{1}{2} n M_{0}\left(\left\|\operatorname{grad} u_{0}\right\|_{\infty}\right)\left\|\Delta u_{0}\right\|_{m}^{2} \\
+C(m, n) \int_{0}^{t} M_{m+1}\left(\|\operatorname{grad} u(s)\|_{\infty}\right)\left(1+\|\operatorname{grad} u(s)\|_{m}^{m}\right) \\
\times\|\Delta u(s)\|_{m}^{2}\left\|\operatorname{grad} u_{t}(s)\right\|_{m} d s \\
+\int_{0}^{t}\|\operatorname{grad} f(s)\|_{m}\left\|\operatorname{grad} u_{t}(s)\right\|_{m} d s,
\end{gathered}
$$

where we have used (A.3) and $m \geqq N$.

Taking the $L^{2}$-inner product of (1.1) with $u_{t}$ yields

$$
\begin{aligned}
& \frac{1}{2} \frac{d}{d t}\left\|u_{t}(t)\right\|^{2}+\lambda\left\|\operatorname{grad} u_{t}(t)\right\|^{2} \\
& \quad-\sum_{i, j=1}^{n}\left(a_{i \jmath}(\operatorname{grad} u(t)) u_{i \jmath}(t), u_{t}(t)\right)+c\left\|u_{t}(t)\right\|^{2} \\
& \quad \leqq\|f(t)\|\left\|u_{t}(t)\right\| .
\end{aligned}
$$

Since, in view of (A.2), $-\sum_{i, j=1}^{n}\left(a_{i j}(\operatorname{grad} u) u_{i j}, u_{t}\right)$ can be written

$$
\begin{aligned}
& \frac{1}{2} \frac{d}{d t} \sum_{i, j=1}^{n}\left(a_{i j}(\operatorname{grad} u) u_{i}, u_{j}\right)-\frac{1}{2} \sum_{i, j, \ell=1}^{n}\left(\frac{\partial a_{i j}}{\partial \eta_{\ell}}(\operatorname{grad} u) u_{\ell t} u_{i}, u_{j}\right) \\
& \quad+\sum_{i, j, \ell=1}^{n}\left(\frac{\partial a_{i j}}{\partial \eta_{\ell}}(\operatorname{grad} u) u_{\jmath \ell} u_{i}, u_{t}\right)
\end{aligned}
$$

integration of (4.22) with respect to $t$ gives

$$
\begin{gathered}
\frac{1}{2}\left\|u_{t}(t)\right\|^{2}+\frac{1}{2} a_{0}\left(\|\operatorname{grad} u(t)\|_{\infty}\right)\|\operatorname{grad} u(t)\|^{2} \\
\quad+\lambda \int_{0}^{t}\left\|\operatorname{grad} u_{t}(s)\right\|^{2} d s+c \int_{0}^{t}\left\|u_{t}(s)\right\|^{2} d s \\
\leqq \frac{1}{2}\left\|v_{0}\right\|^{2}+\frac{1}{2} n M_{0}\left(\left\|\operatorname{grad} u_{0}\right\|_{\infty}\right)\left\|\operatorname{grad} u_{0}\right\|^{2}
\end{gathered}
$$




$$
\begin{aligned}
& +C(n) \int_{0}^{t} M_{1}\left(\|\operatorname{grad} u(s)\|_{\infty}\right)\|\operatorname{grad} u(s)\|_{N} \\
& \quad \times\left(\left\|u_{t}(s)\right\|\|\Delta u(s)\|+\left\|\operatorname{grad} u_{t}(s)\right\|\|\operatorname{grad} u(s)\|\right) d s \\
& +\int_{0}^{t}\|f(s)\|\left\|u_{t}(s)\right\| d s
\end{aligned}
$$

(use Lemma 2.2 (i)).

We now introduce

$$
\|u\|_{m+1}^{2}=\|u\|^{2}+\|\operatorname{grad} u\|_{m}^{2}
$$

and

$$
\|\mid \operatorname{grad} u\|_{m+1}^{2}=\|\operatorname{grad} u\|^{2}+\|\Delta u\|_{m}^{2} .
$$

(it is easy to see that $\|\cdot\| \|_{m+1}$ is an equivalent norm to $\|\cdot\|_{m+1}$ ). Combining (4.21) and (4.23) we get

$$
\begin{aligned}
& \left\|\left|u_{t}(t)\left\|\left.\right|_{m+1} ^{2}+a_{0}\left(\|\operatorname{grad} u(t)\|_{\infty}\right)\right\|\|\operatorname{grad} u(t)\| \|_{m+1}^{2}\right.\right. \\
& +2 \lambda \int_{0}^{t}\|\| \operatorname{grad} u_{t}(s)\left\|_{m+1}^{2} d s+2 c \int_{0}^{t}\right\|\left\|u_{t}(s)\right\| \|_{m+1}^{2} d s \\
& \leqq\left\|v_{0}\right\|\left\|_{m+1}^{2}+n M_{0}\left(\left\|\operatorname{grad} u_{0}\right\|_{\infty}\right)\right\|\left\|\operatorname{grad} u_{0}\right\|_{m+1}^{2} \\
& +2 \int_{0}^{t}\||f(s)|\|_{m+1}\left|\left\|u_{t}(s) \mid\right\|_{m+1} d s\right. \\
& +C(m, n) \int_{0}^{t} M_{m+1}\left(\|\operatorname{grad} u(s)\|_{\infty}\right)\left(1+\|\operatorname{grad} u(s)\|_{m}^{m}\right) \\
& \times\left.|||\operatorname{grad} u(s)|||_{m+1}^{2}||\left|u_{t}(s)\right|\right|_{m+1} d s .
\end{aligned}
$$

We next take the $m$-inner product of (1.1) with $-\Delta u$; then

$$
\begin{aligned}
\sum_{|\alpha| \leqq m}( & \left.D_{x}^{\alpha} u_{t t}, D_{x}^{\alpha}(-\Delta u)\right)+\lambda \sum_{|\alpha| \leqq m}\left(D_{x}^{\alpha} \Delta u_{t}, D_{x}^{\alpha} \Delta u\right) \\
& +\sum_{|\alpha| \leqq m} \sum_{i, j=1}^{n}\left(a_{i j}(\operatorname{grad} u) D_{x}^{\alpha} u_{i j}, D_{x}^{\alpha} \Delta u\right) \\
& +\sum_{|\alpha| \leqq m} \sum_{i, j=1}^{n}\left(D_{x}^{\alpha}\left\{a_{i j}(\operatorname{grad} u) u_{i j}\right\}-a_{i j}(\operatorname{grad} u) D_{x}^{\alpha} u_{i j}, D_{x}^{\alpha} \Delta u\right) \\
& +c \sum_{|\alpha| \leqq m}\left(D_{\alpha}^{\alpha} u_{t}, D_{x}^{\alpha}(-\Delta u)\right)+\sum_{|\alpha| \leqq m}\left(D_{x}^{\alpha} f, D_{x}^{\alpha} \Delta u\right) \\
\equiv & J_{1}+J_{2}+J_{3}+J_{4}+J_{5}+J_{6} \\
= & 0 .
\end{aligned}
$$

It is easy to see the following:

$$
J_{1}=\frac{d}{d t}\left(\operatorname{grad} u_{t}(t), \operatorname{grad} u(t)\right)_{m}-\left\|\operatorname{grad} u_{t}(t)\right\|_{m}^{2},
$$




$$
\begin{aligned}
& J_{2}=\frac{\lambda}{2} \frac{d}{d t}\|\Delta u(t)\|_{m}^{2}, \\
& J_{5}=\frac{c}{2} \frac{d}{d t}\|\operatorname{grad} u(t)\|_{m}^{2},
\end{aligned}
$$

$$
J_{6}=-(\operatorname{grad} f(t), \operatorname{grad} u(t))_{m} \geqq-\|\operatorname{grad} f(t)\|_{m}\|\operatorname{grad} u(t)\|_{m} .
$$

By Lemma 2.4 (ii), $J_{4}$ can be estimated below as $I_{4}$;

$$
\begin{aligned}
& J_{4} \geqq-C(m, n) M_{m+1}\left(\|\operatorname{grad} u(t)\|_{\infty}\right)\left(1+\|\operatorname{grad} u(t)\|_{m}^{m}\right) \\
& \times\|\Delta u(t)\|_{m}^{2}\|\operatorname{grad} u(t)\|_{m} .
\end{aligned}
$$

Finally, since

$$
\begin{aligned}
J_{3}= & \sum_{|\alpha| \leqq m} \sum_{i, j, k=1}^{n}\left(a_{i \jmath}(\operatorname{grad} u) D_{x}^{\alpha} u_{i k}, D_{x}^{\alpha} u_{j k}\right) \\
& +\sum_{|\alpha| \leqq m} \sum_{i, j, k, \ell=1}^{n}\left(\frac{\partial a_{i \jmath}}{\partial \eta_{\ell}}(\operatorname{grad} u)\left(u_{j \ell} D_{x}^{\alpha} u_{i k}-u_{k \ell} D_{x}^{\alpha} u_{i \uparrow}\right), D_{x}^{\alpha} u_{k}\right),
\end{aligned}
$$

it follows with the aid of Lemma 2.2 (i) and (A.3) that

$$
\begin{aligned}
J_{3} \geqq & a_{0}\left(\|\operatorname{grad} u(t)\|_{\infty}\right)\|\Delta u(t)\|_{m}^{2} \\
& -C(m, n) M_{1}\left(\|\operatorname{grad} u(t)\|_{\infty}\right)\|\Delta u(t)\|_{N}\|\Delta u(t)\|_{m}\|\operatorname{grad} u(t)\|_{m} .
\end{aligned}
$$

Add (4.26)-(4.31) and integrate the resulting expression; then

$$
\begin{aligned}
& -\left\|\operatorname{grad} u_{t}(t)\right\|_{m}\|\operatorname{grad} u(t)\|_{m}+\frac{\lambda}{2}\|\Delta u(t)\|_{m}^{2} \\
& +\frac{c}{2}\|\operatorname{grad} u(t)\|_{m}^{2}+\int_{0}^{t} a_{0}\left(\|\operatorname{grad} u(s)\|_{\infty}\right)\|\Delta u(s)\|_{m}^{2} d s \\
& \leqq\left\|\operatorname{grad} v_{0}\right\|_{m}\left\|\operatorname{grad} u_{0}\right\|_{m}+\frac{\lambda}{2}\left\|\Delta u_{0}\right\|_{m}^{2}+\frac{c}{2}\left\|\operatorname{grad} u_{0}\right\|_{m}^{2} \\
& +\int_{0}^{t}\left\|\operatorname{grad} u_{t}(s)\right\|_{m}^{2} d s+\int_{0}^{t}\|\operatorname{grad} f(s)\|_{m}\|\operatorname{grad} u(s)\|_{m} d s \\
& +C(m, n) \int_{0}^{t} M_{m+1}\left(\|\operatorname{grad} u(s)\|_{\infty}\right)\left(1+\|\operatorname{grad} u(s)\|_{m}^{m}\right) \\
& \times\|\Delta u(s)\|_{m}^{2}\|\operatorname{grad} u(s)\|_{m} d s,
\end{aligned}
$$

for $0 \leqq t \leqq T$.

By taking the $L^{2}$-inner product of (1.1) with $u$ and integrating with respect to $t$, it is possible to derive

$$
-\left\|u_{t}(t)\right\|\|u(t)\|+\frac{\lambda}{2}\|\operatorname{grad} u(t)\|^{2}+\frac{c}{2}\|u(t)\|^{2}
$$




$$
\begin{aligned}
& +\int_{0}^{t} a_{0}\left(\|\operatorname{grad} u(s)\|_{\infty}\right)\|\operatorname{grad} u(s)\|^{2} d s \\
\leqq & \left\|v_{0}\right\|\left\|u_{0}\right\|+\frac{\lambda}{2}\left\|\operatorname{grad} u_{0}\right\|^{2}+\frac{c}{2}\left\|u_{0}\right\|^{2} \\
& +\int_{0}^{t}\left\|u_{t}(s)\right\|^{2} d s+\int_{0}^{t}\|f(s)\|\|u(s)\| d s \\
& +C(n) \int_{0}^{t} M_{1}\left(\|\operatorname{grad} u(s)\|_{\infty}\right)\|\Delta u(s)\|\|\operatorname{grad} u(s)\|\|u(s)\|_{N} d s,
\end{aligned}
$$

for $0 \leqq t \leqq T$. Hence, (4.32), together with (4.33), gives

$$
\begin{aligned}
& -2\left|\left\|u_{t}(t)||_{m+1}|||u(t)|\right\|_{m+1}+\lambda\right|\|\operatorname{grad} u(t)\|_{m+1}^{2}+c \mid\|u(t)\|_{m+1}^{2} \\
& +2 \int_{0}^{t} a_{0}\left(\|\operatorname{grad} u(s)\|_{\infty}\right)\|\| \operatorname{grad} u(s)\|\|_{m+1}^{2} d s \\
& \leqq 2\left|\left\|v _ { 0 } \left|\left\|_ { m + 1 } \left|\left\|u_{0}\left|\left\|_{m+1}+\lambda\left|\left\|\operatorname{grad} u_{0}\right\|_{m+1}^{2}+c\right|\right\| u_{0}\right|\right\|_{m+1}^{2}\right.\right.\right.\right.\right. \\
& +2 \int_{0}^{t}\left\|\left|u _ { t } ( s ) \left\|_{m+1}^{2} d s+2 \int_{0}^{t}\left|\left\|f ( s ) \left|\left\|_ { m + 1 } \left|\|u(s) \mid\|_{m+1} d s\right.\right.\right.\right.\right.\right.\right.\right. \\
& +C(m, n) \int_{0}^{t} M_{m+1}\left(\|\operatorname{grad} u(s)\|_{\infty}\right)\left(1+\|\operatorname{grad} u(s)\|_{m}^{m}\right) \\
& \times|| \operatorname{grad} u(s)\left|\|_{m+1}^{2}\right||| u(s)||_{m+1} d s
\end{aligned}
$$

for $0 \leqq t \leqq T$.

Now addition of (4.24) and (4.34) $\times 2 c / 5$ yields

$$
\begin{aligned}
& \frac{1}{2}\left\|u_{t}(t)\right\|_{m+1}^{2}+\left(a_{0}\left(\|\operatorname{grad} u(t)\|_{\infty}\right)+\frac{2 c \lambda}{5}\right)\|\mid \operatorname{grad} u(t)\|_{m+1}^{2} \\
& +\frac{2 c^{2}}{25}\left|\|u(t) \mid\|_{m+1}^{2}\right. \\
& +2 \lambda \int_{0}^{t}\|\| \operatorname{grad} u_{t}(s)\left\|_{m+1}^{2} d s+\frac{6 c}{5} \int_{0}^{t}\right\| u_{t}(s) \|_{m+1}^{2} d s \\
& +\int_{0}^{t}\left\{\frac{4}{5} c a_{0}\left(\|\operatorname{grad} u(s)\|_{\infty}\right)-C(m, n) M_{m+1}\left(\|\operatorname{grad} u(s)\|_{\infty}\right)\right. \\
& \times\left(1+\|\operatorname{grad} u(s)\|_{m}^{m}\right)\left(\left\|u_{t}(s)\right\|_{m+1}+\frac{2 c}{5}\left|\|u(s) \mid\|_{m+1}\right)\right\} \\
& \times\|\operatorname{grad} u(s)\|_{m+1}^{2} d s \\
& \leqq\left\|v_{0}\right\|_{m+1}^{2}+n M_{0}\left(\left\|\operatorname{grad} u_{0}\right\|_{\infty}\right)\|\| \operatorname{grad} u_{0} \|_{m+1}^{2} \\
& +\frac{2 c}{5}\left(2 \left|\left\|v _ { 0 } \left|\left\|_ { m + 1 } \left|\left\|u _ { 0 } \left|\left\|\left.\right|_{m+1}+\lambda\left|\left\|\operatorname { g r a d } u _ { 0 } \left|\left\|_{m+1}^{2}+c\left|\left\|u_{0}\right\|\right|_{m+1}^{2}\right)\right.\right.\right.\right.\right.\right.\right.\right.\right.\right.\right.\right. \\
& +2 \int_{0}^{t}\||f(s)|\|_{m+1}\left(\left|\left\|u_{t}(s)\right\|_{m+1}+\frac{2 c}{5}\right|\|u(s)\| \|_{m+1}\right) d s,
\end{aligned}
$$


for $0 \leqq t \leqq T$.

Let us define

$$
\begin{aligned}
D\left(u_{0}, v_{0}, f\right) & \\
= & \left\{\left\|v_{0}\right\|\left\|_{m+1}^{2}+n M_{0}\left(\left\|\operatorname{grad} u_{0}\right\|_{\infty}\right)\right\| \operatorname{grad} u_{0} \|_{m+1}^{2}\right. \\
& +\frac{2 c}{5}\left(2\|\| v_{0}\|\|_{m+1}\left|\left\|u_{0}\right\|\left\|_{m+1}+\lambda\left|\left\|\operatorname{grad} u_{0}\right\|_{m+1}^{2}+c\right|\right\| u_{0}\|\|_{m+1}^{2}\right)\right\}^{1 / 2} \\
& +2 \int_{0}^{\infty}\|f(s)\|_{m+1} d s .
\end{aligned}
$$

We choose a sufficiently large number $\rho$ satisfying

$$
5 \sqrt{2} s_{0} D\left(u_{0}, v_{0}, f\right) / 2 c<\rho,
$$

(where $s_{0}$ is a positive number in (3.17)) and fix it. We next restrict $\left\|u_{0}\right\|_{m+2},\left\|v_{0}\right\|_{m+1}$ and $\int_{0}^{\infty}\|f(s)\|_{m+1} d s$ so that

$$
\frac{1}{5} c a_{0}(\rho)>C(m, n) M_{m+1}(\rho)\left\{1+\left(5 \sqrt{2} D\left(u_{0}, v_{0}, f\right) / 2 c\right)^{m}\right\} D\left(u_{0}, v_{0}, f\right)
$$

holds.

Since

$$
|| u_{0} \mid \|_{m+1} \leqq 5 \sqrt{2} D\left(u_{0}, v_{0}, f\right) / 2 c
$$

and

$$
||\left|v_{0}\right|\left\|_{m+1}+\frac{2 c}{5}||\left|u_{0}\right|\right\|_{m+1} \leqq \sqrt{2} D\left(u_{0}, v_{0}, f\right)
$$

by (4.36), it follows from (4.37) and (4.38) that both

$$
\|\operatorname{grad} u(t)\|_{\infty}<\rho
$$

and

$$
\begin{aligned}
& \frac{2}{5} c a_{0}\left(\|\operatorname{grad} u(t)\|_{\infty}\right) \\
& \quad \begin{array}{l}
>C(m, n) M_{m+1}\left(\|\operatorname{grad} u(t)\|_{\infty}\right)\left(1+\|\operatorname{grad} u(t)\|_{m}^{m}\right) \\
\times\left(\left\|u_{t}(t)\right\|_{m+1}+\frac{2 c}{5}\|u(t)\| \|_{m+1}\right)
\end{array}
\end{aligned}
$$

are true near $t=0$.

Suppose that $\left[0, T_{0}\right)$, with $0<T_{0} \leqq T$, is the maximum interval on 
which both (4.39) and (4.40) are true. Then, either

$$
\left\|\operatorname{grad} u\left(T_{0}\right)\right\|_{\infty}=\rho,
$$

or

$$
\begin{aligned}
& \frac{2}{5} c a_{0}\left(\left\|\operatorname{grad} u\left(T_{0}\right)\right\|_{\infty}\right) \\
& =C(m, n) M_{m+1}(\| \operatorname{grad} \\
& \left.\quad \times\left(T_{0}\right) \|_{\infty}\right)\left(1+\left\|\operatorname{grad} u\left(T_{0}\right)\right\|_{m}^{m}\right) \\
& \times\left(\left\|u_{t}\left(T_{0}\right)\right\|\left\|_{m+1}+\frac{2 c}{5}\right\| u\left(T_{0}\right) \|_{m+1}\right) .
\end{aligned}
$$

If (4.41) is true, then Lemma 2.1 is applicable to $(4.35)\left(0 \leqq t \leqq T_{0}\right)$ with

$$
\begin{aligned}
& F(t)=\frac{1}{\sqrt{2}}\left\{\left\|u_{t}(t)\right\|_{m+1}^{2}+\frac{4 c^{2}}{25}|\|u(t)\||_{m+1}^{2}\right\}^{1 / 2} \\
& G(t)=4\|\| f(t) \mid \|_{m+1}
\end{aligned}
$$

and

$$
\begin{aligned}
H= & \left.\left\|v_{0}\right\|\right|_{m+1} ^{2}+n M_{0}\left(\left\|\operatorname{grad} u_{0}\right\|_{\infty}\right)\|\| \operatorname{grad} u_{0} \|\left.\right|_{m+1} ^{2} \\
& +\frac{2 c}{5}\left(2\|\| v_{0}\left\|\left.\right|_{m+1}\right\|\left|u_{0}\left\|\left.\right|_{m+1}+\lambda\right\|\left\|\operatorname{grad} u_{0}\right\|\right|_{m+1}^{2}+c\left\|u_{0}\right\| \|_{m+1}^{2}\right) ;
\end{aligned}
$$

so that

$$
\begin{aligned}
F(t) & =\frac{1}{\sqrt{2}}\left\{\left\|\left|u _ { t } ( t ) \left\|_{m+1}^{2}+\frac{4 c^{2}}{25}\left|\|u(t) \mid\|_{m+1}^{2}\right\}^{1 / 2}\right.\right.\right.\right. \\
& \leqq H^{1 / 2}+\frac{1}{2} \int_{0}^{t} G(s) d s \leqq D\left(u_{0}, v_{0}, f\right)
\end{aligned}
$$

on $\left[0, T_{0}\right]$. In particular, (4.43) gives, with the use of (3.17) and (4.37),

$$
\begin{aligned}
\left\|\operatorname{grad} u\left(T_{0}\right)\right\|_{\infty} & \leqq s_{0}\left\|\operatorname{grad} u\left(T_{0}\right)\right\|_{N} \leqq s_{0}\left\|u\left(T_{0}\right)\right\| \|_{m+1} \\
& \leqq 5 \sqrt{2} s_{0} D\left(u_{0}, v_{0}, f\right) / 2 c<\rho,
\end{aligned}
$$

which contradicts (4.41).

On the other hand, let (4.42) hold. The same procedure as above leads us to (4.43) for $0 \leqq t \leqq T_{0}$, so that

$$
\left\|\operatorname{grad} u\left(T_{0}\right)\right\|_{m} \leqq 5 \sqrt{2} D\left(u_{0}, v_{0}, f\right) / 2 c
$$

and 


$$
\|\| u_{t}\left(T_{0}\right)\|\|_{m+1}+\frac{2 c}{5} \mid\left\|u\left(T_{0}\right)\right\|_{m+1} \leqq 2 D\left(u_{0}, v_{0}, f\right) .
$$

Hence, in view of (4.38) and $\left\|\operatorname{grad} u\left(T_{0}\right)\right\|_{\infty}<\rho$, it follows that

$$
\begin{aligned}
\frac{2}{5} c a_{0}\left(\left\|\operatorname{grad} u\left(T_{0}\right)\right\|_{\infty}\right)-C(m, n) M_{m+1}\left(\left\|\operatorname{grad} u\left(T_{0}\right)\right\|_{\infty}\right)\left(1+\left\|\operatorname{grad} u\left(T_{0}\right)\right\|_{m}^{m}\right) \\
\times\left(\left\|u_{t}\left(T_{0}\right) \mid\right\|_{m_{+1}}+\frac{2 c}{5}\|\| u\left(T_{0}\right)\|\|_{m+1}\right) \\
>\frac{2}{5} c a_{0}(\rho)-2 C(m, n) M_{m+1}(\rho)\left\{1+\left(5 \sqrt{2} D\left(u_{0}, v_{0}, f\right) / 2 c\right)^{m}\right\} D\left(u_{0}, v_{0}, f\right) \\
>0,
\end{aligned}
$$

which contradicts (4.42). Therefore, both (4.39) and (4.40) are true on [0,T]. Again applying Lemma 2.1 to $(4.35)(0 \leqq t \leqq T)$ with

$$
\begin{aligned}
F(t)= & \left\{\frac{1}{2}\left|\left\|u_{t}(t)\right\|\right|_{m+1}^{2}+\left(a_{0}(\rho)+\frac{2}{5} c \lambda\right)\|\operatorname{grad} u(t)\|_{m+1}^{2}\right. \\
& +\frac{2 c^{2}}{25}\|\| u(t)\left\|_{m+1}^{2}+2 \lambda \int_{0}^{t}\right\| \operatorname{grad} u_{t}(s) \|_{m+1}^{2} d s \\
& \left.+\frac{6 c}{5} \int_{0}^{t}\|\| u_{t}(s)\|\|_{m+1}^{2} d s+\frac{2}{5} c a_{0}(\rho) \int_{0}^{t}\|\operatorname{grad} u(s)\|_{m+1}^{2} d s\right\}^{1 / 2}
\end{aligned}
$$

and $G(t), H(t)$ as before, we get

$$
F(t) \leqq D\left(u_{0}, v_{0}, f\right), \quad 0 \leqq t \leqq T .
$$

Since $T$ is an arbitrary number and $D\left(u_{0}, v_{0}, f\right)$ is independent of $T$ (see definition (4.36)), estimate (4.44) assures the existence of a unique global solution $u$ of (1.1)-(1.3) satisfying (1.4)-(1.7). Recalling (4.36), (4.37) and (4.38), we obtain the conclusions of Theorem II.

Remark 4.3. Let us consider more general equations than (1.1);

$$
\begin{aligned}
& u_{t t}-\lambda \Delta u_{t}-\sum_{i, j=1}^{n} a_{i j}\left(x, t, u, u_{t}, \operatorname{grad} u\right) u_{i j}+b\left(x, t, u, u_{t}, \operatorname{grad} u\right) \\
& =f, \quad x \in R^{n}, \quad t \geqq 0 .
\end{aligned}
$$

By making some appropriate conditions on $a_{i j}$ and $b$, our method developed in $\S \S 3$ and 4 will apply to initial value problems for (4.45).

\section{§5. Asymptotic behavior}

This section is devoted to the proof of Theorem III. Let $\delta$ be the 
positive constant in Theorem II. Suppose that $f \equiv 0$ and the data $u_{0}$ and $v_{0}$ satisfy

$$
\left\|u_{0}\right\|_{m+2} \leqq \delta \text { and }\left\|v_{0}\right\|_{m+1} \leqq \delta
$$

By Theorem II, there exists a unique solution $u$ of (1.1)-(1.3) satisfying

$$
\|\operatorname{grad} u(t)\|_{\infty} \leqq \rho, \quad t \geqq 0,
$$

and

$$
\begin{aligned}
& \left\|u_{t}(t)\right\|_{m+1}^{2}+\|u(t)\|_{m+2}^{2}+\int_{0}^{t}\left\|u_{t}(s)\right\|_{m+2}^{2} d s+\int_{0}^{t}\|\operatorname{grad} u(s)\|_{m+1}^{2} d s \\
& \leqq C_{1}, \quad t \geqq 0
\end{aligned}
$$

with some $\rho, C_{1}>0$ (see (4.39) and (4.44)).

However, it is expected that $u$ will decay to zero as $t \rightarrow \infty$ by virtue of dissipative terms $-\lambda \Delta u_{t}(\lambda>0)$ and $c u_{t}(c>0)$. To investigate the decay properties of $u$, we employ the weighted energy method and seek a weight function $\phi(t) \rightarrow \infty$ as $t \rightarrow \infty$ satisfying

$$
\phi(t)\left\{\left\|u_{t}(t)\right\|_{m+1}^{2}+\|\operatorname{grad} u(t)\|_{m+1}^{2}\right\}<\infty,
$$

for large $t$. See also Yamada [21], [22].

Let $\phi(t) \in C^{3}[0, \infty)$ be a monotone increasing and non-negative function. Taking the $m$-inner product of (1. 1) (with $f \equiv 0$ ) with $-\phi(t) \Delta u_{t}$, we obtain, as in the derivation of (4.21),

$$
\begin{aligned}
& \phi(t)\left\{\left\|\operatorname{grad} u_{t}(t)\right\|_{m}^{2}+a_{0}(\rho)\|\Delta u(t)\|_{m}^{2}\right\} \\
& \quad+2 \lambda \int_{0}^{t} \phi(s)\left\|\Delta u_{t}(s)\right\|_{m}^{2} d s+2 c \int_{0}^{t} \phi(s)\left\|\operatorname{grad} u_{t}(s)\right\|_{m}^{2} d s \\
& \leqq \\
& \quad \phi(0)\left\{\left\|\operatorname{grad} v_{0}\right\|_{m}^{2}+n M_{0}(\rho)\left\|\Delta u_{0}\right\|_{m}^{2}\right\} \\
& \quad+\int_{0}^{t} \phi^{\prime}(s)\left\|\operatorname{grad} u_{t}(s)\right\|_{m}^{2} d s+n M_{0}(\rho) \int_{0}^{t} \phi^{\prime}(s)\|\Delta u(s)\|_{m}^{2} d s \\
& \quad+C(m, n, \rho, \delta) \int_{0}^{t} \phi(s)\|\Delta u(s)\|_{m}^{2}\left\|\operatorname{grad} u_{t}(s)\right\|_{m} d s, \quad t \geqq 0,
\end{aligned}
$$

where we have used (5.1) and (5.2). As in $\S 4.2$, set

$$
\|u\|_{m+1}^{2}=\|u\|^{2}+\|\operatorname{grad} u\|_{m}^{2} \quad \text { for } u \in H^{m+1},
$$

and

$$
\|\operatorname{grad} u\|_{m+1}^{2}=\|\operatorname{grad} u\|^{2}+\|\Delta u\|_{m}^{2} \quad \text { for } u \in H^{m+2}
$$


$\||\cdot|\|_{m+1}$ being an equivalent norm to $\|\cdot\|_{m+1}$. It is also possible to derive the following inequality:

$$
\begin{aligned}
& \phi(t)\left\{\left\|u_{t}(t)\right\|_{m+1}^{2}+a_{0}(\rho)\|\operatorname{grad} u(t)\|_{m+1}^{2}\right\} \\
& +2 \lambda \int_{0}^{t} \phi(s)\|\| \operatorname{grad} u_{t}(s)\|\|_{m+1}^{2} d s+2 c \int_{0}^{t} \phi(s)\left\||| u_{t}(s)\right\|_{m+1}^{2} d s \\
& \leqq \phi(0)\left\{\left\|\mid v_{0}\right\|\left\|_{m+1}^{2}+n M_{0}(\rho)\right\| \operatorname{grad} u_{0} \|_{m+1}^{2}\right\} \\
& +\int_{0}^{t} \phi^{\prime}(s)\|\| u_{t}(s)\left\|_{m+1}^{2} d s+n M_{0}(\rho) \int_{0}^{t} \phi^{\prime}(s)\right\| \operatorname{grad} u(s) \|_{m+1}^{2} d s \\
& +C(m, n, \rho, \delta) \int_{0}^{t} \phi(s)\left|\|\operatorname{grad} u(s)\|\left\|_{m+1}^{2} \mid\right\| u_{t}(s) \|_{m_{+1}} d s, \quad t \geqq 0,\right.
\end{aligned}
$$

(cf. (4.24)).

Now we set $\phi(t)=t$ in (5.4) and make use of (5.2). Then

$$
\begin{aligned}
& t\left\{\left\|\mid u_{t}(t)\right\|_{m+1}^{2}+a_{0}(\rho)\|\operatorname{grad} u(t)\| \|_{m+1}^{2}\right\} \\
& +2 \lambda \int_{0}^{t} s\left\|\operatorname{grad} u_{t}(s)\right\|_{m+1}^{2} d s+2 c \int_{0}^{t} s\left\|u_{t}(s)\right\|_{m+1}^{2} d s \\
& \leqq C_{2}+C_{3} \int_{0}^{t} s\left\|\left|\operatorname { g r a d } u ( s ) \left\|| _ { m + 1 } ^ { 2 } \left|\left\|u_{t}(s) \mid\right\|_{m+1} d s\right.\right.\right.\right. \\
& \leqq C_{2}+c \int_{0}^{t} s \mid\left\|u_{t}(s)\right\|_{m+1}^{2} d s+\frac{C_{3}^{2}}{4 c} \int_{0}^{t} s\|\| \operatorname{grad} u(s)\|\|_{m+1}^{4} d s,
\end{aligned}
$$

for some constants $C_{2}, C_{3}>0$. After some rearrangements of (5.5), we get for some $C_{4}>0$

$$
\begin{aligned}
& t\left\{\left\|u_{t}(t)\right\|\left\|_{m+1}^{2}+a_{0}(\rho)\right\| \mid \operatorname{grad} u(t)\|\|_{m+1}^{2}\right\} \\
& \quad+2 \lambda \int_{0}^{t} s\left\|\mid \operatorname{grad} u_{t}(s)\right\|\left\|_{m+1}^{2} d s+c \int_{0}^{t} s\right\| u_{t}(s) \|_{m+1}^{2} d s \\
& \leqq \\
& C_{2}+C_{4} \int_{0}^{t} s a_{0}(\rho)\|\operatorname{grad} u(s)\|_{m+1}^{2}\|\operatorname{grad} u(s)\|_{m+1}^{2} d s .
\end{aligned}
$$

Consequently, by Gronwall's inequality, the right-hand side of (5.6) is bounded by $C_{2} \exp \left(C_{4} \int_{0}^{t}\|\mid \operatorname{grad} u(s)\|_{m+1}^{2} d s\right)$. Since $\int_{0}^{\infty}\|\operatorname{grad} u(s)\|_{m+1}^{2} d s<\infty$ by (5.2), it is easily seen that

$$
\sup _{t \geq 0}\left\{t\left\|u_{t}(t)\right\|_{m+1}^{2}+t\|\operatorname{grad} u(t)\|_{m+1}^{2}+\int_{0}^{t} s\left\|u_{t}(s)\right\|_{m+2}^{2} d s\right\}<\infty
$$

which asserts (1.8) and (1.9).

In order to show (1.10) and (1.11), we take the $m$-inner product of (1.1) $(f \equiv 0)$ with $-\phi^{\prime}(t) \Delta u$ and integrate the resulting expression with respect to $t$; then we can derive 


$$
\begin{aligned}
-2 \phi^{\prime}(t) & \left\|\operatorname{grad} u_{t}(t)\right\|_{m}\|\operatorname{grad} u(t)\|_{m}+\lambda \phi^{\prime}(t)\|\Delta u(t)\|_{m}^{2} \\
& +\left(c \phi^{\prime}(t)-\phi^{\prime \prime}(t)\right)\|\operatorname{grad} u(t)\|_{m}^{2} \\
& +\int_{0}^{t}\left(\phi^{\prime \prime \prime}(s)-c \phi^{\prime \prime}(s)\right)\|\operatorname{grad} u(s)\|_{m}^{2} d s \\
& +\int_{0}^{t}\left(2 a_{0}(\rho) \phi^{\prime}(s)-\lambda \phi^{\prime \prime}(s)\right)\|\Delta u(s)\|_{m}^{2} d s \\
\leqq & 2 \phi^{\prime}(0)\left\|\operatorname{grad} v_{0}\right\|_{m}\left\|\operatorname{grad} u_{0}\right\|_{m}+\lambda \phi^{\prime}(0)\left\|\Delta u_{0}\right\|_{m}^{2} \\
& +\left(c \phi^{\prime}(0)-\phi^{\prime \prime}(0)\right)\left\|\operatorname{grad} u_{0}\right\|_{m}^{2}+2 \int_{0}^{t} \phi^{\prime}(s)\left\|\operatorname{grad} u_{t}(s)\right\|_{m}^{2} d s \\
& +C(m, n, \rho, \delta) \int_{0}^{t} \phi^{\prime}(s)\|\Delta u(s)\|_{m}^{2}\|\operatorname{grad} u(s)\|_{m} d s .
\end{aligned}
$$

Let $k$ be a positive parameter. Addition of (5.3) and (5.8) $\times k$ yields

$$
\begin{aligned}
\phi(t) \| \operatorname{grad} & u_{t}(t)\left\|_{m}^{2}+\left(a_{0}(\rho) \phi(t)+\lambda k \phi^{\prime}(t)\right)\right\| \Delta u(t) \|_{m}^{2} \\
& -2 k \phi^{\prime}(t)\left\|\operatorname{grad} u_{t}(t)\right\|_{m}\|\operatorname{grad} u(t)\|_{m} \\
& +k\left(c \phi^{\prime}(t)-\phi^{\prime \prime}(t)\right)\|\operatorname{grad} u(t)\|_{m}^{2}+2 \lambda \int_{0}^{t} \phi(s)\left\|\Delta u_{t}(s)\right\|_{m}^{2} d s \\
& +\int_{0}^{t}\left(2 c \phi(s)-\phi^{\prime}(s)-2 k \phi^{\prime}(s)\right)\left\|\operatorname{grad} u_{t}(s)\right\|_{m}^{2} d s \\
& +\int_{0}^{t}\left\{\left(2 k a_{0}(\rho)-n M_{0}(\rho)\right) \phi^{\prime}(s)-k \phi^{\prime \prime}(s)\right\}\|\Delta u(s)\|_{m}^{2} d s \\
& +k \int_{0}^{t}\left(\phi^{\prime \prime \prime}(s)-c \phi^{\prime \prime}(s)\right)\|\operatorname{grad} u(s)\|_{m}^{2} d s \\
\leqq & \phi(0)\left\|\operatorname{grad} v_{0}\right\|_{m}^{2}+\left(n M_{0}(\rho) \phi(0)+\lambda k \phi^{\prime}(0)\right)\left\|\Delta u_{0}\right\|_{m}^{2} \\
& +2 k \phi^{\prime}(0)\left\|\operatorname{grad} v_{0}\right\|_{m}\left\|\operatorname{grad} u_{0}\right\|_{m}+k\left(c \phi^{\prime}(0)-\phi^{\prime \prime}(0)\right)\left\|\operatorname{grad} u_{0}\right\|_{m}^{2} \\
& +C(m, n, \rho, \delta) \int_{0}^{t}\|\Delta u(s)\|_{m}^{2}\left\{\phi(s)\left\|\operatorname{grad} u_{t}(s)\right\|_{m}\right. \\
& \left.+k \phi^{\prime}(s)\|\operatorname{grad} u(s)\|_{m}\right\} d s .
\end{aligned}
$$

Since (5.2) and (5.7) are true, it follows by putting $\phi(t)=t^{2}$ in (5.9) that

$$
\begin{aligned}
& \frac{1}{2} t^{2}\left\|\operatorname{grad} u_{t}(t)\right\|_{m}^{2}+a_{0}(\rho) t^{2}\|\Delta u(t)\|_{m}^{2} \\
& \quad+2 \lambda \int_{0}^{t} s^{2}\left\|\Delta u_{t}(s)\right\|_{m}^{2} d s+2 c \int_{0}^{t} s^{2}\left\|\operatorname{grad} u_{t}(s)\right\|_{m}^{2} d s \\
& \quad+2 \int_{0}^{t}\left(2 k a_{0}(\rho)-n M_{0}(\rho)\right) s\|\Delta u(s)\|_{m}^{2} d s \\
& \leqq C_{5}+C_{6} \int_{0}^{t}\|\Delta u(s)\|_{m}^{2}\left\{s^{2}\left\|\operatorname{grad} u_{t}(s)\right\|_{m}+2 k s\|\operatorname{grad} u(s)\|_{m}\right\} d s,
\end{aligned}
$$

for some $C_{5}$ and $C_{6}>0$. (Note that $C_{6}$ can be taken independent of $k$.) 
On the other hand, from (5.2) and (5.7), we have

$$
\begin{aligned}
& C_{6} \int_{0}^{t} s^{2}\|\Delta u(s)\|_{m}^{2}\left\|\operatorname{grad} u_{t}(s)\right\|_{m} d s \\
& \quad \leqq c \int_{0}^{t} s^{2}\left\|\operatorname{grad} u_{t}(s)\right\|_{m}^{2} d s+\frac{C_{6}^{2}}{4 c} \int_{0}^{t} s^{2}\|\Delta u(s)\|_{m}^{4} d s \\
& \quad \leqq c \int_{0}^{t} s^{2}\left\|\operatorname{grad} u_{t}(s)\right\|_{m}^{2} d s+C_{7} \int_{0}^{t} s\|\Delta u(s)\|_{m}^{2} d s,
\end{aligned}
$$

with some $C_{7}>0$ (independent of $k$ ) and

$$
\begin{aligned}
& k C_{6} \int_{0}^{t} s\|\Delta u(s)\|_{m}^{2}\|\operatorname{grad} u(s)\|_{m} d s \\
& \quad \leqq \frac{1}{2} \int_{0}^{t} s\|\Delta u(s)\|_{m}^{2} d s+\frac{k^{2} C_{6}^{2}}{2} \int_{0}^{t} s\|\Delta u(s)\|_{m}^{2}\|\operatorname{grad} u(s)\|_{m}^{2} d s \\
& \quad \leqq \frac{1}{2} \int_{0}^{t} s\|\Delta u(s)\|_{m}^{2} d s+\frac{k^{2} C_{6}^{2}}{2} \sup _{s \geq 0}\left\{s\|\Delta u(s)\|_{m}^{2}\right\} \int_{0}^{t}\|\operatorname{grad} u(s)\|_{m}^{2} d s \\
& \quad \leqq \frac{1}{2} \int_{0}^{t} s\|\Delta u(s)\|_{m}^{2} d s+C_{8},
\end{aligned}
$$

with some $C_{8}>0$.

Therefore, it becomes from (5.10), (5.11) and (5.12) that

$$
\begin{aligned}
& \frac{1}{2} t^{2}\left\|\operatorname{grad} u_{t}(t)\right\|_{m}^{2}+a_{0}(\rho) t^{2}\|\Delta u(t)\|_{m}^{2} \\
& \quad+2 \lambda \int_{0}^{t} s^{2}\left\|\Delta u_{t}(s)\right\|_{m}^{2} d s+c \int_{0}^{t} s^{2}\left\|\operatorname{grad} u_{t}(s)\right\|_{m}^{2} d s \\
& \quad+\int_{0}^{t}\left\{2\left(2 k a_{0}(\rho)-n M_{0}(\rho)\right)-C_{7}-\frac{1}{2}\right\} s\|\Delta u(s)\|_{m}^{2} d s \\
& \leqq \\
& C_{5}+C_{8},
\end{aligned}
$$

which enables us to get (1.10) and (1.11) by taking a sufficiently large $k$ such that

$$
2\left(2 k a_{0}(\rho)-n M_{0}(\rho)\right)-C_{7}-\frac{1}{2}>0 .
$$

Remark 5.1. In this section we have assumed that $f \equiv 0$. However, if $f(t)$ tends to zero (in an appropriate sense) as $t \rightarrow \infty$, we can apply the same method to obtain decay estimates of solutions to (1.1).

Remark 5.2. The weighted energy method developed in this section is found in the work of Uesaka [23], where the total energy decay of solutions to linear wave equations with first-order dissipative terms is treated. 


\section{Chapter II. Quasilinear Wave Equations: An Approach by the Viscosity Method}

\section{§1. Problems and results}

In this chapter we discuss the relations between initial value problems

$$
\begin{array}{ll}
u_{t t}^{\lambda}-\lambda \Delta u_{t}^{\lambda}-\sum_{i, j=1}^{n} a_{i j}\left(\operatorname{grad} u^{\lambda}\right) u_{i j}^{\lambda}+c u_{t}^{\lambda}=f, & x \in R^{n}, \quad t \geqq 0, \\
u^{\lambda}(x, 0)=u_{0}(x), & x \in R^{n}, \\
u_{t}^{\lambda}(x, 0)=v_{0}(x) & x \in R^{n},
\end{array}
$$

with $1 \geqq \lambda \geqq 0$ (we use the superscript $\lambda$ of $u^{\lambda}$ to specify the dependence on $\lambda$ ) and initial value problems to quasilinear wave equations

$$
\begin{array}{ll}
u_{t t}^{0}-\sum_{i, j=1}^{n} a_{i j}\left(\operatorname{grad} u^{0}\right) u_{i j}^{0}+c u_{t}^{0}=f, & x \in R^{n}, t \geqq 0, \\
u^{0}(x, 0)=u_{0}(x), & x \in R^{n}, \\
u_{t}^{0}(x, 0)=v_{0}(x), & x \in R^{n} .
\end{array}
$$

Here we put the same assumptions (A.1)-(A.3) on $a_{i j}$. One of the typical examples of (1.1) $)_{0}$ whose coefficients $a_{i j}$ satisfy (A.1)-(A.3) is the following:

$$
u_{t t}^{0}-\sum_{i=1}^{n} \frac{\partial}{\partial x_{i}}\left(\frac{u_{i}^{0}}{\sqrt{1+\left|\operatorname{grad} u^{0}\right|^{2}}}\right)+c u_{t}^{0}=f,
$$

which describes the nonlinear vibration of a string for $n=1$ and that of a membrane for $n=2$.

In Chapter I we have obtained the local and global existence results of solutions to $(1.1)_{\lambda}-(1.3)_{\lambda}$. The strong dissipative term $-\lambda \Delta u_{t}^{\lambda}(\lambda>0)$ in (1.1) $\lambda$ may be regarded as the 'viscosity' term (see e.g. Greenberg, MacCamy and Mizel [7]), so that we employ the viscosity method to get the local and global existence of solutions to (1.1) $)_{0}-(1.3)_{0}$. In other words, by letting $\lambda \downarrow 0$ in $(1.1)_{\lambda}$, we shall show that the limiting function of $u^{\lambda}$ is a solution of $(1.1)_{0}-(1.3)_{0}$.

We state our results.

Theorem I. Let $0<\lambda \leqq 1$ and let $\left(u_{0}, v_{0}, f\right) \in H^{m+2} \times H^{m+1} \times\left\{C^{1}([0, \infty)\right.$; $\left.\left.H^{m}\right) \cap C\left([0, \infty) ; H^{m+1}\right)\right\}$.

(i) There exists a positive constant $T_{0}$, independent of $\lambda$, such that the initial value problem (1.1) ${ }_{\lambda}-(1.3)_{\lambda}$ has a unique solution 
$u^{\lambda} \in C\left(\left[0, T_{0}\right] ; H^{m+2}\right) \cap C^{1}\left(\left[0, T_{0}\right] ; H^{m+1}\right) \cap C^{1}\left(\left(0, T_{0}\right] ; H^{m+2}\right) \cap C^{2}\left(\left(0, T_{0}\right] ; H^{m}\right)$.

Furthermore, for all $0<\lambda \leqq 1,\left\{u^{\lambda}\right\}$ and $\left\{u_{t}^{\lambda}\right\}$ are bounded in $C\left(\left[0, T_{0}\right] ; H^{m+2}\right)$ and $C\left(\left[0, T_{0}\right] ; H^{m+1}\right)$, respectively.

(ii) There exist

$$
\begin{array}{ll}
u^{0}(t)=\lim _{\lambda \downarrow 0} u^{\lambda}(t), & \text { strongly in } H^{m+1} \text { and weakly in } H^{m+2}, \\
& \text { uniformly for } t \in\left[0, T_{0}\right],
\end{array}
$$

and

$$
\begin{array}{ll}
u_{t}^{0}(t)=\lim _{2 \downarrow 0} u_{t}^{\lambda}(t), & \text { strongly in } H^{m} \text { and weakly in } H^{m+1}, \\
& \text { uniformly for } t \in\left[0, T_{0}\right],
\end{array}
$$

$u^{0}$ being a unique solution of $(1.1)_{0}-(1.3)_{0}$ such that

$$
u^{0} \in C^{i}\left(\left[0, T_{0}\right] ; H^{m+2-i}\right), \quad i=0,1,2 .
$$

In particular, if $f \in C^{i}\left([0, \infty) ; H^{m+1-i}\right)$ with $i=0,1, \cdots, m$, then $u^{0} \in$ $C^{i}\left(\left[0, T_{0}\right] ; H^{m+2-i}\right)$ with $i=0,1, \cdots, m+2$.

Remark 1.1. As to the strong convergence of $u^{\lambda}$ (resp. $u_{t}^{\lambda}$ ) to $u^{0}$ (resp. $u_{t}^{0}$ ), it is possible to show

$$
\begin{array}{r}
\left\|u_{t}^{\lambda}(t)-u_{t}^{0}(t)\right\|_{m}^{2}+\left\|\operatorname{grad}\left(u^{\lambda}(t)-u^{0}(t)\right)\right\|_{m}^{2} \leqq C \lambda, \\
\text { for } 0 \leqq t \leqq T_{0},
\end{array}
$$

where $C$ is a positive constant independent of $\lambda$ and $t$.

Remark 1.2. Let $\left(u_{0}, v_{0}, f\right)$ belong to $H^{m+2} \times H^{m+1} \times\left\{C^{1}\left([0, \infty), H^{m}\right) \cap\right.$ $\left.C\left([0, \infty) ; H^{m+1}\right)\right\}$. It is interesting to see that $u^{0}$ is better behaved than $u^{2}$ at $t=0$, for $u_{t t}^{2}$ need not be strongly continuous in $H^{m}$ at $t=0$.

Remark 1.3. Since $m \geqq[n / 2]+1$, it follows from Sobolev's lemma (Lemma 2.2 in Chap. I) that $u^{0}$ constructed in Theorem I is twice continuously differentiable in $(x, t) \in R^{n} \times\left[0, T_{0}\right]$ and, therefore, it becomes a classical solution of $(1.1)_{0}-(1.3)_{0}$.

TheOREM II. Let $c>0,1 \geqq \lambda>0$ and $\left(u_{0}, v_{0}, f\right) \in H^{m+2} \times H^{m+1} \times$ $\left\{C^{1}\left([0, \infty) ; H^{m}\right) \cap C\left([0, \infty) ; H^{m+1}\right)\right\}$.

(i) There exists a positive constant $\delta_{0}$, depending on $m, n, c$ and $D_{\eta}^{\alpha} a_{i j}$ $(|\alpha| \leqq m+1)$, but not $\lambda$, such that, if the data $\left(u_{0}, v_{0}, f\right)$ satisfy

$$
\max \left\{\left\|u_{0}\right\|_{m+2},\left\|v_{0}\right\|_{m+1}, \int_{0}^{\infty}\|f(s)\|_{m+1} d s\right\} \leqq \delta_{0},
$$


then the initial value problem (1.1) $-(1.3)_{2}$ has a unique solution

$$
\begin{array}{r}
u^{\lambda} \in C\left([0, \infty) ; H^{m+2}\right) \cap C^{1}\left([0, \infty) ; H^{m+1}\right) \cap C^{1}\left((0, \infty) ; H^{m+2}\right) \\
\cap C^{2}\left((0, \infty) ; H^{m}\right) .
\end{array}
$$

Furthermore, $u^{\lambda}$ satisfies

$$
\sup _{\substack{t \geq 0 \\ 1 \geqq \lambda>0}}\left\{\left\|u^{\lambda}(t)\right\|_{m+2}+\left\|u_{t}^{\lambda}(t)\right\|_{m+1}\right\}<\infty,
$$

and

$$
\sup _{1 \geq \lambda>0} \int_{0}^{\infty}\left(\left\|\operatorname{grad} u^{2}(s)\right\|_{m+1}^{2}+\left\|u_{t}^{\lambda}(s)\right\|_{m+1}^{2}\right) d s<\infty .
$$

(ii) For any $T>0$, there exist

$$
\begin{array}{ll}
u^{0}(t)=\lim _{\lambda \downarrow 0} u^{\lambda}(t), & \text { strongly in } H^{m+1} \text { and weakly in } H^{m+2}, \\
& \text { uniformly for } t \in[0, T],
\end{array}
$$

and

$$
\begin{array}{ll}
u_{t}^{0}(t)=\lim _{\lambda \downarrow 0} u_{t}^{\lambda}(t), & \text { strongly in } H^{m} \text { and weakly in } H^{m+1}, \\
& \text { uniformly for } t \in[0, T],
\end{array}
$$

$u^{0}$ being a unique solution of $(1.1)_{0}-(1.3)_{0}$ such that

$$
u^{0} \in C^{i}\left([0, \infty) ; H^{m+2-i}\right) \text { with } i=0,1,2 \text {. }
$$

In addition, $u^{0}$ satisfies

$$
\sup _{t \geqq 0}\left\{\left\|u^{0}(t)\right\|_{m+2}+\left\|u_{t}^{0}(t)\right\|_{m+1}\right\}<\infty,
$$

and

$$
\int_{0}^{\infty}\left(\left\|\operatorname{grad} u^{0}(s)\right\|_{m+1}^{2}+\left\|u_{t}^{0}(s)\right\|_{m+1}^{2}\right) d s<\infty
$$

In particular, if $f \in C^{i}\left([0, \infty), H^{m+1-i}\right)$ with $i=0,1, \cdots, m$, then $u^{0} \in$ $C^{i}\left([0, \infty) ; H^{m+2-i}\right)$ with $i=0,1, \cdots, m+2$.

Remark 1.4. As in Remark 1.1, we can show

$$
\begin{aligned}
\left\|u_{t}^{\lambda}(t)-u_{t}^{0}(t)\right\|_{m}^{2}+\left\|\operatorname{grad}\left(u^{\lambda}(t)-u^{0}(t)\right)\right\|_{m}^{2} \leqq C e^{C^{\prime} t} \lambda, & \\
& \text { for } t \geqq 0,
\end{aligned}
$$

where $C, C^{\prime}$ are positive constants independent of $\lambda$ and $t$. 
Remark 1.5. Greenberg, MacCamy and Mizel [7] has first proposed the equation

$$
u_{t t}-\sigma\left(u_{x}\right) u_{x x}-\lambda u_{x t x}=0, \quad \lambda>0,
$$

to study the quasilinear wave equation

$$
u_{t t}-\sigma\left(u_{x}\right) u_{x x}=0,
$$

where $\sigma$ is a positive smooth function. However, they have not obtained any results about the relations between these two equations. For the mixed problem, Davis [2] has succeeded in getting the similar results to Theorem $I$ in the special case $n=1$ and $\sigma(r)=a_{1}+a_{2} r^{2}$ with $a_{1}, a_{2}>0$.

By Theorem II, if the data $\left(u_{0}, v_{0}, f\right)$ are sufficiently small, then the

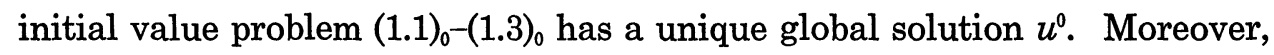
by (1.7) and Sobolev's lemma, not only $u^{0}$ but also its derivatives up to the second-order are bounded in $(x, t) \in R^{n} \times[0, \infty)$. However, because of the dissipative term $c u_{t}^{0}(c>0)$, we may expect that $u^{0}$ actually decays to zero as $t \rightarrow \infty$ when $f(t)$ tends to zero as $t \rightarrow \infty$. For simplicity, we set $f \equiv 0$ to investigate the asymptotic properties of solutions to $(1.1)_{0}-(1.3)_{0}$.

THEOREM III. Suppose that $f \equiv 0$ and $c>0$. Let $u^{0}$ be the solution of $(1.1)_{0}-(1.3)_{0}$ in Theorem II. Then $u^{0}$ decays like

$$
\begin{array}{ll}
\left\|\operatorname{grad} u^{0}(t)\right\|_{m+1}^{2}=O\left(t^{-1}\right) & \text { as } t \longrightarrow \infty, \\
\left\|u_{t}^{0}(t)\right\|_{m+1}^{2}=O\left(t^{-1}\right) & \text { as } t \longrightarrow \infty, \\
\left\|\Delta u^{0}(t)\right\|_{m}^{2}=O\left(t^{-2}\right) & \text { as } t \longrightarrow \infty, \\
\left\|\operatorname{grad} u_{t}^{0}(t)\right\|_{m}^{2}=O\left(t^{-2}\right) & \text { as } t \longrightarrow \infty .
\end{array}
$$

We can also estimate the rate of the decay of $u^{0}$ with respect to the supremum norm.

Corollary. Under the conditions of Theorem III, $u^{0}$ decays like

$$
\begin{aligned}
& \left\|u^{0}(t)\right\|_{\infty}= \begin{cases}O\left(t^{-n / 2 N}\right) & \text { if } n \geqq 2, \\
O\left(t^{-1 / 4}\right) & \text { if } n=1,\end{cases} \\
& \left\|u_{i}^{0}(t)\right\|_{\infty}, \quad\left\|u_{t}^{0}(t)\right\|_{\infty}=O\left(t^{-(n+2 N) / 4 N}\right), \quad 1 \leqq i \leqq n,
\end{aligned}
$$

as $t \rightarrow \infty$, where $N=[n / 2]+1$. 
Remark 1.6. Recently, Matsumura [12], [13] has obtained some decay estimates of solutions to quasilinear evolution equations of type (1.1). Our results (Theorem III and its Corollary) are sharper than the corresponding ones in [12] and [13].

\section{§2. Proofs of existence theorems}

\subsection{Proof of Theorem I}

Let $u_{0} \in H^{m+2}, v_{0} \in H^{m+1}$ and $f \in C^{1}\left([0, \infty) ; H^{m}\right) \cap C\left([0, \infty) ; H^{m+1}\right)$. Theorem I in Chapter I shows the existence of a solution $u^{\lambda}$ of (1.1) $)_{\lambda}-(1.3)_{\lambda}$ on a certain interval $[0, \tau]$. However, the existence interval $[0, \tau]$ depends on $\lambda$ and $\tau=\tau_{\lambda}$ may tend to zero as $\lambda \downarrow 0$ (see (4.5) and (4.7) in Chapter I). Therefore, in order to prove the assertions of Theorem I (i), we have to choose an appropriate interval $\left[0, T_{0}\right]$ (with $T_{0}>0$ independent of $\lambda$ ), on which both $\left\|u^{\lambda}(t)\right\|_{m+2}$ and $\left\|u_{t}^{\lambda}(t)\right\|_{m+1}$ can be bounded by a positive constant independent of $\lambda$. (Recall the arguments of Chap. I, § 4.)

To this aim, we shall make use of inequality (I.4.24) (which means (4.24) in Chapter I): we have

$$
\begin{aligned}
& \left\|\mid u_{t}^{\lambda}(t)\right\|_{m+1}^{2}+a_{0}\left(\left\|\operatorname{grad} u^{\lambda}(t)\right\|_{\infty}\right)\|\| \operatorname{grad} u^{\lambda}(t)\|\|_{m+1}^{2} \\
& +2 \lambda \int_{0}^{t}\|\| \operatorname{grad} u_{t}^{\lambda}(s) \|\left.\right|_{m+1} ^{2} d s \\
& \leqq\left.\left\|v_{0}\right\|\right|_{m+1} ^{2}+n M_{0}\left(\left\|\operatorname{grad} u_{0}\right\|_{\infty}\right)\|\| \operatorname{grad} u_{0} \|_{m+1}^{2} \\
& +\left.2|c| \int_{0}^{t}||\left|u_{t}^{\lambda}(s)\right|\right|_{m+1} ^{2} d s+\left.2 \int_{0}^{t}|||f(s)|||_{m+1}||\left|u_{t}^{2}(s)\right|\right|_{m+1} d s \\
& +C(m, n) \int_{0}^{t} M_{m+1}\left(\left\|\operatorname{grad} u^{\lambda}(s)\right\|_{\infty}\right)\left(1+\|\| \operatorname{grad} u^{\lambda}(s) \|_{m+1}^{m}\right) \\
& \times\left\|\left|\operatorname { g r a d } u ^ { \lambda } ( s ) \left\|\left.\right|_{m+1} ^{2}||\left|u_{t}^{\lambda}(s) \|\right|_{m+1} d s\right.\right.\right.
\end{aligned}
$$

with a suitable constant $C(m, n)>0$, depending on $m, n$, but not on $\lambda$. (In what follows, $C(\alpha, \beta, \cdots)$ denotes various positive constants depending on $\alpha, \beta, \cdots$, but not on $\lambda_{\text {.) }}$ In (2.1), recall

$$
\||u|\|_{m+1}^{2}=\|u\|^{2}+\|\operatorname{grad} u\|_{m}^{2}
$$

and

$$
\|\operatorname{grad} u\|\left\|_{m+1}^{2}=\right\| \operatorname{grad} u\left\|^{2}+\right\| \Delta u \|_{m}^{2} .
$$

Take a sufficiently large $\rho>0$ such that $\rho \geqq 4\left\|\operatorname{grad} u_{0}\right\|_{\infty}$ and suppose that

$$
\left\|\operatorname{grad} u^{\lambda}(t)\right\|_{\infty} \leqq \rho
$$


is true on $[0, T]$, where $T>0$ is an arbitrary fixed number. Put

$$
E^{2}(t)=\left\|\mid u_{t}^{2}(t)\right\|_{m+1}^{2}+a_{0}(\rho)\left\|\operatorname{grad} u^{2}(t)\right\| \|_{m+1}^{2} .
$$

Then it follows from (2.1) that

$$
\begin{aligned}
E^{2}(t)+ & 2 \lambda \int_{0}^{t}\left\|\operatorname{grad} u_{t}^{\lambda}(s)\right\|_{m+1}^{2} d s \\
\leqq & \left\|v_{0} \mid\right\|_{m+1}^{2}+n M_{0}(\rho)\left\|\operatorname{grad} u_{0}\right\|\left\|_{m+1}^{2}+\int_{0}^{T}\right\| f f(s) \|_{m+1}^{2} d s \\
& +C_{1}(m, n, T)+C_{2}(m, n, \rho) \int_{0}^{t} E^{\lambda}(s)^{(m+3) / 2} d s, \quad 0 \leqq t \leqq T,
\end{aligned}
$$

where we have used the following inequality:

$$
a b \leqq \frac{1}{p} a^{p}+\frac{1}{q} b^{q}, \quad a, b \geqq 0,
$$

with $p>1$ and $1 / p+1 / q=1$. In other words, we have

$$
X(t) \leqq D_{1}+D_{2} \int_{0}^{t} X(s)^{1+\theta} d s,
$$

with

$$
\begin{aligned}
& X(t)=E^{\lambda}(t)+2 \lambda \int_{0}^{t} \mid\left\|\operatorname{grad} u_{t}^{\lambda}(s)\right\|_{m+1}^{2} d s, \\
& D_{1}=\|\| v_{0}\left\|_{m+1}^{2}+n M_{0}(\rho)\right\| \operatorname{grad} u_{0}\left\|_{m+1}^{2}+\int_{0}^{T} \mid\right\| f(s) \|_{m+1}^{2} d s+C_{1}(m, n, T), \\
& D_{2}=C_{2}(m, n, \rho) \quad \text { and } \theta=\frac{m+1}{2} .
\end{aligned}
$$

Since (2.4) implies

$$
X(t) \leqq D_{1}\left(1-\theta D_{1}^{\theta} D_{2} t\right)^{-1 / \theta}
$$

on $\left[0,1 / \theta D_{1}^{\theta} D_{2}\right)$, we may conclude that

$$
E^{2}(t)+2 \lambda \int_{0}^{t}\left\|\operatorname{grad} u_{t}^{\lambda}(s)\right\|_{m+1}^{2} d s \leqq 2 D_{1}
$$

holds on a certain interval $\left[0, T^{*}\right]$ with $T^{*}\left(<\min \left\{T, 2 /(m+1) D_{1}^{(m+1) / 2} D_{2}\right\}\right)$, independent of $\lambda$. Let $s_{0}$ be the positive number in (I.3.17) and take a positive constant $T_{0}$ satisfying $4 \sqrt{2 D_{1}} s_{0} T_{0} \leqq \rho$ and $T_{0} \leqq T^{*}$. Since

$$
\left\|\operatorname{grad} u^{2}(t)\right\|_{\infty} \leqq\left\|\operatorname{grad} u_{0}\right\|_{\infty}+\int_{0}^{t}\left\|\operatorname{grad} u_{t}^{\lambda}(s)\right\|_{\infty} d s
$$




$$
\begin{aligned}
& \leqq \frac{\rho}{4}+s_{0} \int_{0}^{t}\left\|\operatorname{grad} u_{t}^{\lambda}(s)\right\|_{N} d s \\
& \leqq \frac{\rho}{4}+s_{0} \int_{0}^{t}\|\| u_{t}^{\lambda}(s)\|\|_{m+1} d s,
\end{aligned}
$$

it follows from (2.5) that

$$
\left\|\operatorname{grad} u^{\lambda}(t)\right\|_{\infty} \leqq \frac{\rho}{4}+\sqrt{2 D_{1}} s_{0} T_{0} \leqq \frac{\rho}{2} \quad \text { on }\left[0, T_{0}\right],
$$

which justifies (2.2). Thus, noting the validity of (2.5) on $\left[0, T_{0}\right]$, we complete the proof of (i).

We next prove (ii). Let $1 \geqq \mu \geqq \lambda>0$ and let $u^{2}, u^{\mu}$ be solutions of the corresponding initial value problems. Taking the difference of the two equations yields

$$
\begin{aligned}
& \left(u_{t t}^{\lambda}-u_{t t}^{\mu}\right)-\lambda \Delta\left(u_{t}^{\lambda}-u_{t}^{\mu}\right)+(\mu-\lambda) \Delta u_{t}^{\mu} \\
& \quad-\sum_{i, j=1}^{n}\left\{a_{i j}\left(\operatorname{grad} u^{\lambda}\right)-a_{i j}\left(\operatorname{grad} u^{\mu}\right)\right\} u_{i j}^{\lambda} \\
& \quad-\sum_{i, j=1}^{n} a_{i j}\left(\operatorname{grad} u^{\mu}\right)\left(u_{i j}^{\lambda}-u_{i j}^{\mu}\right)+c\left(u_{t}^{\lambda}-u_{t}^{\mu}\right)=0, \quad 0 \leqq t \leqq T_{0} .
\end{aligned}
$$

Set $v=u^{\lambda}-u^{\mu}$ and take the $m$-inner product of (2.6) with $v_{t}$; then

$$
\begin{aligned}
\sum_{|\alpha| \leqq m}\left(D_{x}^{\alpha} v_{t t}, D_{x}^{\alpha} v_{t}\right)-\lambda \sum_{|\alpha| \leqq m}\left(D_{x}^{\alpha} \Delta v_{t}, D_{x}^{\alpha} v_{t}\right)+(\mu-\lambda) \sum_{|\alpha| \leqq m}\left(D_{x}^{\alpha} \Delta u_{t}^{\mu}, D_{x}^{\alpha} v_{t}\right) \\
\quad-\sum_{|\alpha| \leqq m} \sum_{i, j=1}^{n}\left(D_{x}^{\alpha}\left\{a_{i j}\left(\operatorname{grad} u^{\lambda}\right)-a_{i j}\left(\operatorname{grad} u^{\mu}\right)\right\} u_{i j}^{\alpha}, D_{x}^{\alpha} v_{t}\right) \\
\quad-\sum_{|\alpha| \leqq m} \sum_{i, j=1}^{n}\left(D_{x}^{\alpha}\left\{a_{i j}\left(\operatorname{grad} u^{\mu}\right) v_{i j}\right\}-a_{i j}\left(\operatorname{grad} u^{\mu}\right) D_{x}^{\alpha} v_{i j}, D_{x}^{\alpha} v_{t}\right) \\
\quad-\sum_{|\alpha| \leqq m} \sum_{i, j=1}^{n}\left(a_{i j}\left(\operatorname{grad} u^{\mu}\right) D_{x}^{\alpha} v_{i j}, D_{x}^{\alpha} v_{t}\right)+c \sum_{|\alpha| \leqq m}\left(D_{x}^{\alpha} v_{t}, D_{x}^{\alpha} v_{t}\right) \\
\equiv I_{1}+I_{2}+I_{3}+I_{4}+I_{5}+I_{6}+I_{7} \\
=0, \quad 0 \leqq t \leqq T_{0} .
\end{aligned}
$$

We shall arrange each $I_{i}(1 \leqq i \leqq 7)$. It is easy to show

$$
\begin{aligned}
& I_{1}=\frac{1}{2} \frac{d}{d t}\left\|v_{t}(t)\right\|_{m}^{2}, \\
& I_{2}=\lambda\left\|\operatorname{grad} v_{t}(t)\right\|_{m}^{2}, \\
& I_{3} \geqq-(\mu-\lambda)\left\|\Delta u_{t}^{\mu}(t)\right\|_{m}\left\|v_{t}(t)\right\|_{m}, \\
& I_{7}=c\left\|v_{t}(t)\right\|_{m}^{2} \geqq-|c|\left\|v_{t}(t)\right\|_{m}^{2} .
\end{aligned}
$$

By virtue of (I. 2.7), $I_{4}$ can be estimated as follows; 


$$
\begin{aligned}
I_{4} & \geqq-C(m, n) M_{m+1}\left(\left\|\operatorname{grad} u^{2}(t)\right\|_{\infty}+\left\|\operatorname{grad} u^{\mu}(t)\right\|_{\infty}\right)\left\|\Delta u^{2}(t)\right\|_{m} \\
& \times\left(1+\left\|\operatorname{grad} u^{2}(t)\right\|_{m}^{m}+\left\|\operatorname{grad} u^{\mu}(t)\right\|_{m}^{m}\right)\|\operatorname{grad} v(t)\|_{m}\left\|v_{t}(t)\right\|_{m} .
\end{aligned}
$$

Lemma 2.4 (iii) in Chapter I gives

$$
\begin{array}{r}
I_{5} \geqq-C(m, n) M_{m}\left(\left\|\operatorname{grad} u^{\mu}(t)\right\|_{\infty}\right)\left(1+\left\|\operatorname{grad} u^{\mu}(t)\right\|_{m}^{m-1}\right)\left\|\Delta u^{\mu}(t)\right\|_{m} \\
\times\|\operatorname{grad} v(t)\|_{m}\left\|v_{t}(t)\right\|_{m} .
\end{array}
$$

Finally, since

$$
\begin{aligned}
I_{6}= & \sum_{|\alpha| \leqq m} \sum_{i, j=1}^{n}\left(a_{i j}\left(\operatorname{grad} u^{\mu}\right) D_{x}^{\alpha} v_{i}, D_{x}^{\alpha} v_{j t}\right) \\
& +\sum_{|\alpha| \leqq m} \sum_{i, j, k=1}^{n}\left(\frac{\partial a_{i j}}{\partial \eta_{k}}\left(\operatorname{grad} u^{\mu}\right) u_{j k}^{\mu} D_{x}^{\alpha} v_{i}, D_{x}^{\alpha} v_{t}\right) \\
= & \frac{1}{2} \frac{d}{d t} \sum_{|\alpha| \leqq m} \sum_{i, j=1}^{n}\left(a_{i j}\left(\operatorname{grad} u^{\mu}\right) D_{x}^{\alpha} v_{i}, D_{x}^{\alpha} v_{\jmath}\right) \\
& -\frac{1}{2} \sum_{|\alpha| \leqq m} \sum_{i, j, k=1}^{n}\left(\frac{\partial a_{i j}}{\partial \eta_{k}}\left(\operatorname{grad} u^{\mu}\right) u_{k t}^{\mu} D_{x}^{\alpha} v_{i}, D_{x}^{\alpha} v_{\jmath}\right) \\
& +\sum_{|\alpha| \leqq m} \sum_{i, j, k=1}^{n}\left(\frac{\partial a_{i j}}{\partial \eta_{k}}\left(\operatorname{grad} u^{\mu}\right) u_{j k}^{\mu} D_{x}^{\alpha} v_{i}, D_{x}^{\alpha} v_{t}\right),
\end{aligned}
$$

it follows that

$$
\begin{aligned}
I_{6} \geqq \frac{1}{2} \frac{d}{d t} \sum_{|\alpha| \leqq m} \sum_{i, j=1}^{n}\left(a_{i j}\left(\operatorname{grad} u^{\mu}(t)\right) D_{x}^{\alpha} v_{t}(t), D_{x}^{\alpha} v_{j}(t)\right) \\
-C(m, n) M_{1}\left(\left\|\operatorname{grad} u^{\mu}(t)\right\|_{\infty}\right)\left\{\left\|\operatorname{grad} u_{t}^{\mu}(t)\right\|_{N}\|\operatorname{grad} v(t)\|_{m}^{2}\right. \\
\left.+\left\|\Delta u^{\mu}(t)\right\|_{N}\|\operatorname{grad} v(t)\|_{m}\left\|v_{t}(t)\right\|_{m}\right\},
\end{aligned}
$$

where we have used Sobolev's lemma.

Thus, by combining (2.7)-(2.13), it is possible to derive the following estimate with the aid of (A.3), (2.2) and (2.5);

$$
\begin{aligned}
& \left\|v_{t}(t)\right\|_{m}^{2}+a_{0}(\rho)\|\operatorname{grad} v(t)\|_{m}^{2}+2 \lambda \int_{0}^{t}\left\|\operatorname{grad} v_{t}(s)\right\|_{m}^{2} d s \\
& \leqq \mu^{2} \int_{0}^{t}\left\|\Delta u_{t}^{\mu}(s)\right\|_{m}^{2} d s+C(m, n, \rho) \int_{0}^{t}\left\{\left\|v_{t}(s)\right\|_{m}^{2}\right. \\
& \left.+a_{0}(\rho)\|\operatorname{grad} v(s)\|_{m}^{2}\right\} d s .
\end{aligned}
$$

Since $\mu \int_{0}^{T_{0}}\left\|\Delta u_{t}^{\mu}(s)\right\|_{m}^{2} d s$ is bounded by some positive constant independent of $\mu$ (see (2.5)), (2.14), together with Gronwall's inequality, implies that

$$
u^{0}(t)=\lim _{\lambda \downarrow 0} u^{\lambda}(t) \text { exists in } H^{m+1} \text {, uniformly for } t \in\left[0, T_{0}\right]
$$


and that

$$
u_{t}^{0}(t)=\lim _{\lambda \downarrow 0} u_{t}^{\lambda}(t) \text { exists in } H^{m} \text {, uniformly for } t \in\left[0, T_{0}\right] .
$$

Clearly, $u^{0} \in C\left(\left[0, T_{0}\right] ; H^{m+1}\right) \cap C^{1}\left(\left[0, T_{0}\right] ; H^{m}\right)$ from (2.15) and (2.16). (Letting $\lambda \downarrow 0$ in (2.14) and applying Gronwall's inequality we get estimate (1.4) in Remark 1.1.)

Furthermore, since $\left\|u_{t}^{\lambda}(t)\right\|_{m+1}^{2}+a_{0}(\rho)\left\|\operatorname{grad} u^{\lambda}(t)\right\|_{m+1}^{2}$ is bounded by a positive constant independent of $\lambda$ on $\left[0, T_{0}\right]$ (see (2.3) and (2.5)), it can be shown that, as $\lambda \downarrow 0$,

$$
u^{\lambda}(t) \rightarrow u^{0}(t) \text { in } H^{m+2} \text {, uniformly for } t \in\left[0, T_{0}\right],
$$

and

$$
u_{t}^{\lambda}(t) \rightarrow u_{t}^{0}(t) \text { in } H^{m+1} \text {, uniformly for } t \in\left[0, T_{0}\right],
$$

where $\rightarrow$ means weak convergence. Hence, $u^{0} \in C_{w}\left(\left[0, T_{0}\right] ; H^{m+2}\right) \cap C_{w}^{1}\left(\left[0, T_{0}\right]\right.$; $H^{m+1}$ ) from (2.17) and (2.18).

Now from Lemma 2.4 (i) in Chapter I, $\left\{B\left(u^{\lambda}\right)\right\}=\left\{\sum_{i, j=1}^{n} a_{i j}\left(\operatorname{grad} u^{\lambda}\right) u_{i j}^{\lambda}\right\}$ is bounded in $C\left(\left[0, T_{0}\right] ; H^{m}\right)$ for all $0<\lambda \leqq 1$. We shall show that

$$
B\left(u^{\lambda}(t)\right) \rightarrow B\left(u^{0}(t)\right) \text { in } H^{m} \text {, uniformly on }\left[0, T_{0}\right] .
$$

Since $m \geqq[n / 2]+1$, it follows from (2.15) that

$$
u_{i j}^{2}(t) \longrightarrow u_{i j}^{0}(t) \text { in } L^{2} \text {, uniformly for } t \in\left[0, T_{0}\right]
$$

and

$$
\operatorname{grad} u^{2}(x, t) \longrightarrow \operatorname{grad} u^{0}(x, t) \text { uniformly for }(x, t) \in R^{n} \times\left[0, T_{0}\right]
$$

(use Sobolev's lemma). Hence, for any $\phi \in C_{0}^{\infty}$,

$$
\left(B\left(u^{\lambda}(t)\right), \phi\right)_{m}=\sum_{|\alpha| \leqq m}(-1)^{|\alpha|}\left(\sum_{i, j=1}^{n} a_{i j}\left(\operatorname{grad} u^{\lambda}(t)\right) u_{i j}^{\lambda}(t), D_{x}^{2 \alpha} \phi\right)
$$

converges to

$$
\sum_{|\alpha| \leqq m}(-1)^{|\alpha|}\left(\sum_{i, j=1}^{n} a_{i j}\left(\operatorname{grad} u^{0}(t)\right) u_{i j}^{0}(t), D_{x}^{2 \alpha} \phi\right)=\dot{(}\left(B\left(u^{0}(t)\right), \phi\right)_{m}
$$

uniformly for $t \in\left[0, T_{0}\right]$ as $\lambda \downarrow 0$. This shows (2.19), because $C_{0}^{\infty}$ is dense in $H^{m}$.

We are ready to prove that $u^{0}$ is a solution of $(1.1)_{0}-(1.3)_{0}$. Note that the next identity holds for any $\phi \in C_{0}^{\infty}$; 


$$
\begin{aligned}
\left(u_{t}^{\lambda}(t), \phi\right)_{m}= & \left(v_{0}, \phi\right)_{m}+\lambda\left(\Delta u^{\lambda}(t), \phi\right)_{m}-\lambda\left(\Delta u_{0}, \phi\right)_{m} \\
& -c\left(u^{\lambda}(t), \phi\right)_{m}+c\left(u_{0}, \phi\right)_{m} \\
& +\int_{0}^{t}\left(B\left(u^{\lambda}(s)\right)+f(s), \phi\right)_{m} d s, \quad 0 \leqq t \leqq T_{0} .
\end{aligned}
$$

Letting $\lambda \downarrow 0$ in (2.22) and making use of convergence properties (2.15), (2.16), (2.17) and (2.19), we get

$$
\begin{aligned}
\left(u_{t}^{0}(t), \phi\right)_{m}= & \left(v_{0}, \phi\right)_{m}-c\left(u^{0}(t), \phi\right)_{m}+c\left(u_{0}, \phi\right)_{m} \\
& +\int_{0}^{t}\left(B\left(u^{0}(s)\right)+f(s), \phi\right)_{m} d s .
\end{aligned}
$$

This implies that $t \rightarrow u_{t}^{0}(t)$ is weakly continuously differentiable in $H^{m}$ and that

$$
\left(u_{t t}^{0}(t), \phi\right)_{m}=\left(B\left(u^{0}(t)\right)-c u_{t}^{0}(t)+f(t), \phi\right)_{m}, \quad 0 \leqq t \leqq T_{0},
$$

for any $\phi \in C_{0}^{\infty}$. Since $C_{0}^{\infty}$ is dense in $H^{m}$, initial value problem (1.1)(1.3) $)_{0}$ has a unique solution $u^{0}$ (in the sense of (2.23) for any $\phi \in H^{m}$ ) such that

$$
u^{0} \in C\left(\left[0, T_{0}\right] ; H^{m+1}\right) \cap C^{1}\left(\left[0, T_{0}\right] ; H^{m}\right) \cap C_{w}^{i}\left(\left[0, T_{0}\right] ; H^{m+2-i}\right)
$$

with $i=0,1,2$.

Before proving that $u^{0}$ actually belongs to the class $C^{t}\left(\left[0, T_{0}\right] ; H^{m+2-t}\right)$, $i=0,1,2$, it is very convenient to show the uniqueness of solutions to $(1.1)_{0}-(1.3)_{0}$ within the class (2.24). Let $u^{0}, v^{0}$ be two solutions of $(1.1)_{0}-$ (1.3) $)_{0}$ satisfying (2.24). If we put $w^{0}=u^{0}-v^{0}$, we have

$$
\begin{gathered}
w_{t t}^{0}-\sum_{i, j=1}^{n}\left\{a_{i j}\left(\operatorname{grad} u^{0}\right)-a_{i j}\left(\operatorname{grad} v^{0}\right)\right\} u_{i j}^{0} \\
-\sum_{i, j=1}^{n} a_{i j}\left(\operatorname{grad} v^{0}\right) w_{i j}^{0}+c w_{t}^{0}=0
\end{gathered}
$$

Take the $m$-inner product of (2.25) with $w_{t}^{0}$. (This is possible because $w_{t}^{0}$ belongs to $C\left(\left[0, T_{0}\right] ; H^{m}\right)$ and each term of the left-hand side of (2.25) belongs to $C_{w}\left(\left[0, T_{0}\right] ; H^{m}\right)$.) Then, as in the derivation of (2.14), we can show

$$
\begin{aligned}
& \left\|w_{t}^{0}(t)\right\|_{m}^{2}+a_{0}(\rho)\left\|\operatorname{grad} w^{0}(t)\right\|_{m}^{2} \\
& \quad \leqq C \int_{0}^{t}\left\{\left\|w_{t}^{0}(s)\right\|_{m}^{2}+a_{0}(\rho)\left\|\operatorname{grad} w^{0}(s)\right\|_{m}^{2}\right\} d s, \quad 0 \leqq t \leqq T_{0},
\end{aligned}
$$

with some $\rho, C>0$, which, together with Gronwall's inequality, implies $\left\|w_{t}^{0}(t)\right\|_{m}=\left\|\operatorname{grad} w^{0}(t)\right\|_{m}=0$, i.e., $w^{0}=0$. Thus we have shown the uniqueness of solutions to $(1.1)_{0}-(1.3)_{0}$ within the class (2.24). 
Now we shall prove that the solution $u^{0}$ constructed above actually belongs to the class $C^{i}\left(\left[0, T_{0}\right] ; H^{m+2-i}\right)$ with $i=0,1,2$. We make use of the following inequality whose derivation is essentially the same as that of (I. 4.24):

$$
\begin{aligned}
& \left\|u_{t}^{\alpha}(t) \mid\right\|_{m+1}^{2}+\sum_{|\alpha| \leqq m} \sum_{i, j, k=1}^{n}\left(a_{i j}\left(\operatorname{grad} u^{\alpha}(t)\right) D_{x}^{\alpha} u_{i k}^{\alpha}(t), D_{x}^{\alpha} u_{j k}^{\alpha}(t)\right) \\
& +\sum_{i, j=1}^{n}\left(a_{i j}\left(\operatorname{grad} u^{2}(t)\right) u_{i}^{\lambda}(t), u_{j}^{2}(t)\right)+2 \lambda \int_{0}^{t}\left\|\operatorname{grad} u_{t}^{\lambda}(s)\right\|_{m+1}^{2} d s \\
& \leqq||\left|v_{0}\right| \|_{m+1}^{2}+\sum_{|\alpha| \leqq m} \sum_{i, j, k=1}^{n}\left(a_{i j}\left(\operatorname{grad} u_{0}\right) D_{x}^{\alpha} u_{0, i k}, D_{x}^{\alpha} u_{0, j k}\right) \\
& +\sum_{i, j=1}^{n}\left(a_{i j}\left(\operatorname{grad} u_{0}\right) u_{0, i}, u_{0, j}\right) \\
& +\left.2 \int_{0}^{t}|||f(s)|||_{m+1}||\left|u_{t}^{2}(s)\right|\right|_{m+1} d s+2|c| \int_{0}^{t}\left|\left\|u_{t}^{2}(s) \mid\right\|_{m+1}^{2} d s\right. \\
& +C(m, n) \int_{0}^{t} M_{m+1}\left(\left\|\operatorname{grad} u^{\lambda}(s)\right\|_{\infty}\right)\left(1+\left\|\operatorname{grad} u^{\lambda}(s)\right\|_{m}^{m}\right) \\
& \times\left\||| \operatorname{grad} u^{\lambda}(s)\right\|\left\|_{m+1}^{2}\right\| \mid u_{t}^{\lambda}(s)\|\|_{m+1} d s .
\end{aligned}
$$

Note that each integral of the right-hand side of (2.26) is bounded by $C t$ with some $C>0$, independent of $\lambda$ (recall (2.5)). Letting $\lambda \downarrow 0$ in (2.26), we can conclude by convergence properties (2.15)-(2.21) and (A.3) that

$$
\begin{aligned}
&\left\|\mid u_{t}^{0}(t)\right\| \|_{m+1}^{2}+\sum_{|\alpha| \leqq m} \sum_{i, j, k=1}^{n}\left(a_{i \jmath}\left(\operatorname{grad} u^{0}(t)\right) D_{x}^{\alpha} u_{i k}^{0}(t), D_{x}^{\alpha} u_{j k}^{0}(t)\right) \\
& \quad+\sum_{i, j=1}^{n}\left(a_{i \jmath}\left(\operatorname{grad} u^{0}(t)\right) u_{i}^{0}(t), u_{j}^{0}(t)\right) \\
& \leqq\left\|v_{0} \mid\right\|_{m+1}^{2}+\sum_{|\alpha| \leqq m} \sum_{i, j, k=1}^{n}\left(a_{i j}\left(\operatorname{grad} u_{0}\right) D_{x}^{\alpha} u_{0, i k}, D_{x}^{\alpha} u_{0, j k}\right) \\
&+\sum_{i, j=1}^{n}\left(a_{i j}\left(\operatorname{grad} u_{0}\right) u_{0, i}, u_{0, j}\right)+C t .
\end{aligned}
$$

We set $b_{i j}(x)=a_{i j}\left(\operatorname{grad} u_{0}(x)\right)$ and provide $H^{m+2}$ with a new inner product defined by

$$
(u, v)_{b, m+2}=\sum_{|\alpha| \leqq m} \sum_{i, j, k=1}^{n}\left(b_{i j} D_{x}^{\alpha} u_{i k}, D_{x}^{\alpha} v_{j k}\right)+\sum_{i, j=1}^{n}\left(b_{i j} u_{i}, v_{j}\right)+(u, v) .
$$

The associated norm is defined by

$$
\|u\|_{b, m+2}=\left\{(u, u)_{b, m+2}\right\}^{1 / 2},
$$

which is equivalent to $\|\cdot\|_{m+2}$. Recall that

$$
u^{0} \in C\left(\left[0, T_{0}\right] ; H^{m+1}\right) \cap C_{w}\left(\left[0, T_{0}\right] ; H^{m+2}\right) \cap C^{1}\left(\left[0, T_{0}\right] ; H^{m}\right) \cap C_{w}^{1}\left(\left[0, T_{0}\right] ; H^{m+1}\right) .
$$


Since

$$
\lim _{t \downarrow 0} \operatorname{grad} u^{0}(x, t)=\operatorname{grad} u_{0}(x) \text { uniformly in } x \in R^{n},
$$

by Sobolev's lemma, it follows by letting $t \downarrow 0$ in (2.27) that

$$
\begin{gathered}
\limsup _{t \downarrow 0}\left\{\left\||| u_{t}^{0}(t)\right\|_{m+1}^{2}+\left\|u^{0}(t)\right\|_{b, m+2}^{2}\right\} \\
\leqq\left.\left\|v_{0}\right\|\right|_{m+1} ^{2}+\left\|u_{0}\right\|_{b, m+2}^{2} .
\end{gathered}
$$

On the other hand, by the weak continuity of $t \rightarrow u^{0}(t)$ in $H^{m+2}$ and $t \rightarrow$ $u_{t}^{0}(t)$ in $H^{m+1}$, we have

$$
\left\{\begin{array}{l}
\liminf _{t \downarrow 0}\left\|u^{0}(t)\right\|_{b, m+2}^{2} \geqq\left\|u_{0}\right\|_{b, m+2}^{2} \\
\liminf _{t \downarrow 0}\left\|u_{t}^{0}(t)\right\|\left\|_{m+1}^{2} \geqq\right\| v_{0}\|\|_{m+1}^{2}
\end{array} .\right.
$$

Hence, (2.28) and (2.29) imply

$$
\left\{\begin{array}{l}
\lim _{t \downarrow 0}\left\|u^{0}(t)\right\|_{b, m+2}=\left\|u_{0}\right\|_{b, m+2} \\
\lim _{t \downarrow 0}\left\|\left|u_{t}^{0}(t)\left\|\left.\right|_{m+1}=\right\|\left\|v_{0}\right\| \|_{m+1} .\right.\right.
\end{array}\right.
$$

Consequently, (2.30), together with the weak continuity of $t \rightarrow u^{0}(t)$ in $H^{m+2}$ and that of $t \rightarrow u_{t}^{0}(t)$ in $H^{m+1}$, yields the strong continuity of $t \rightarrow u^{0}(t)$ in $H^{m+2}$ and that of $t \rightarrow u_{t}^{0}(t)$ in $H^{m+1}$ at $t=0$.

To prove the same result at any $t_{0} \in\left[0, T_{0}\right]$, we consider the initial value problem to $(1.1)_{0}$ for $t \geqq t_{0}$ with initial data $\left\{u^{0}\left(t_{0}\right), u_{t}^{0}\left(t_{0}\right)\right\}$. Then the preceding consideration assures that there exists a unique solution $v^{0}$ in the class (2.24) with $\left[0, T_{0}\right]$ replaced by $\left[t_{0}, T_{0}^{\prime}\right]\left(T_{0}^{\prime}>t_{0}\right)$. Moreover, at $t=$ $t_{0}, v^{0}$ is strongly continuous in $H^{m+2}$ and $v_{t}^{0}$ is strongly continuous in $H^{m+1}$. Hence, by the uniqueness result proved before, we see that $u^{0}$ (resp. $u_{t}^{0}$ ) is strongly right-continuous in $H^{m+2}$ (resp. $H^{m+1}$ ) at $t=t_{0}$.

To prove the left-continuity of $u^{0}$, we consider the next initial value problem

$$
\left\{\begin{array}{l}
v_{t t}^{0}-\sum_{i, j=1}^{n} a_{i j}\left(\operatorname{grad} v^{0}\right) v_{i j}^{0}-c v_{t}^{0}=f\left(T_{0}-t\right), \quad 0 \leqq t \leqq T_{0} \\
v^{0}(0)=u^{0}\left(T_{0}\right) \in H^{m+2} \\
v_{t}^{0}(0)=u_{t}^{0}\left(T_{0}\right) \in H^{m+1}
\end{array}\right.
$$

The existence of a solution $v^{0}$ within the class (2.24) is already known from the above arguments. Moreover, both $t \rightarrow v^{0}(t)$ in $H^{m+2}$ and $t \rightarrow v_{t}^{0}(t)$ in 
$H^{m+1}$ are strongly right-continuous on $\left[0, T_{0}\right)$. On the other hand, the uniqueness result implies $u^{0}(t)=v^{0}\left(T_{0}-t\right)$, which shows that $(1.1)_{0}$ is reversible in $t$. Therefore,

$$
u^{0} \in C^{i}\left(\left[0, T_{0}\right] ; H^{m+2-i}\right), \quad i=0,1 .
$$

Furthermore, it follows from (1.1), with the aid of Lemma 2.4 in Chapter I, that $u_{t t}^{0} \in C\left(\left[0, T_{0}\right] ; H^{m}\right)$.

Finally, it remains to show $u^{0} \in C^{i}\left(\left[0, T_{0}\right] ; H^{m+2-i}\right)(i=0,1, \cdots, m+2)$ if $f \in C^{i}\left([0, \infty) ; H^{m+1-i}\right)(i=0,1, \cdots, m)$. However, this is a direct consequence of the following proposition.

Proposition 2.1. Let $\left(u_{0}, v_{0}, f\right) \in H^{m+2} \times H^{m+1} \times C^{i}\left([0, \infty) ; H^{m+1-i}\right)$ with $i=0,1, \cdots, m$. Suppose that the initial value problem $(1.1)_{0}-(1.3)_{0}$ has a solution $u^{0} \in C^{i}\left([0, T] ; H^{m+2-i}\right)$, with $i=0,1,2$. Then

$$
u^{0} \in C^{i}\left([0, T] ; H^{m+2-i}\right) \quad \text { with } i=0,1, \cdots, m+2 .
$$

The proof of this proposition is given at the end of this section.

Remark 2.1. The viscosity method has produced satisfactory results in various fields. See e.g. Lions [10], Oleinik [16] and Kozhanov [24]. One of the typical applications is found in the work of T. Kato [8], where he has treated the initial value problem for the Navier-Stokes equations by the theory of nonlinear evolution equations to approach the initial value problem for the Euler equation.

The existence result obtained here for initial value problems (1.1)(1.3) $)_{0}$ is not new, but the approach via the viscosity method is new and seems simpler than the existing one due to Dionne [3]. (In [3], precise arguments on the smoothness of coefficients of linear hyperbolic equations are needed.)

Remark 2.2. We can apply the technics developed in this paper to initial value problems for more general quasilinear wave equations

$$
u_{t t}-\sum_{i, j=1}^{n} a_{i \jmath}\left(x, t, u, \operatorname{grad} u, u_{t}\right) u_{i \jmath}+b\left(x, t, u, \operatorname{grad} u, u_{t}\right)=f,
$$

with some appropriate assumptions on $a_{i j}$ and $b$. See also Remark 4.3 in Chapter I.

\subsection{Proof of Theorem II}

Let $c>0,1 \geqq \lambda>0$ and $\left(u_{0}, v_{0}, f\right) \in H^{m+2} \times H^{m+1} \times\left\{C^{1}\left([0, \infty) ; H^{m}\right) \cap\right.$ 
$\left.C\left([0, \infty) ; H^{m+1}\right)\right\}$. To prove (i), it suffices to show that $\left\|u^{2}(t)\right\|_{m+2},\left\|u_{t}^{2}(t)\right\|_{m+1}$, $\int_{0}^{t}\left\|\operatorname{grad} u^{2}(s)\right\|_{m+1}^{2} d s$ and $\int_{0}^{t}\left\|u_{t}^{\lambda}(s)\right\|_{m+1}^{2} d s$ are bounded above by some positive constants (independent of $\lambda$ ) for all $t \geqq 0$.

Recall the arguments in Chapter I, $\S 4$. We first note that (I.4.35) is true with $u$ replaced by $u^{\lambda}$. Set

$$
\delta \equiv \max \left\{| | | v _ { 0 } | \left\|_{m+1},|| \operatorname{grad} u_{0}\left|\left\|_{m+1},||\left|u_{0}\right|\right\|_{m+1}, \int_{0}^{\infty}\|f(s) \mid\|_{m+1} d s\right\}\right.\right.
$$

and

$$
D(\delta) \equiv \delta\left[\left\{1+n M_{0}\left(s_{0} \delta\right)+\frac{2}{5} c(3+c)\right\}^{1 / 2}+2\right] .
$$

We fix an arbitrary $\rho>0$ satisfying $\rho>5 \sqrt{2} s_{0} D(1) / 2 c$ and choose a sufficiently small $0<\delta_{0}<1$ such that

$$
\frac{1}{5} c a_{0}(\rho)>C(m, n) M_{m+1}(\rho)\left\{1+\left(5 \sqrt{2} D\left(\delta_{0}\right) / 2 c\right)^{m}\right\} D\left(\delta_{0}\right),
$$

(cf. (I.4.36) and (I.4.38)). Note that $\delta_{0}$ can be taken depending on $m, n$, $c, \rho$ and $D_{\eta}^{\alpha} a_{i j}(|\alpha| \leqq m+1)$, but not on $\lambda$.

By repeating the procedure in Chapter I, $\S 4.2$, it is found that, if $\delta$ $\leqq \delta_{0}$, then

$$
\begin{aligned}
& \frac{1}{2}\|\| u_{t}^{2}(t)\|\|_{m+1}^{2}+a_{0}(\rho)\left\|\operatorname{grad} u^{2}(t)\right\|\left\|_{m+1}^{2}+\frac{2 c^{2}}{25}\right\|\left\|u^{2}(t)\right\|_{m+1}^{2} \\
& \quad+2 \lambda \int_{0}^{t}\|\| \operatorname{grad} u_{t}^{2}(s)\left\|_{m+1}^{2} d s+\frac{6 c}{5} \int_{0}^{t}\right\|\left\|u_{t}^{2}(s)\right\| \|_{m+1}^{2} d s \\
& \quad+\frac{2}{5} c a_{0}(\rho) \int_{0}^{t}\left\|\operatorname{grad} u^{2}(s)\right\|_{m+1}^{2} d s \\
& \leqq D\left(\delta_{0}\right)^{2}, \quad \text { for all } t \geqq 0,
\end{aligned}
$$

(cf. (I. 4.44)), which assures (1.5) and (1.6). Thus the proof of (i) is complete.

The proof of (ii) is essentially the same as that of Theorem I (ii), so we shall only sketch it here.

Since (2.14) is true on $[0, \infty)$ for all $1 \geqq \mu>\lambda>0$ and $t \geqq 0$, it follows with the use of (2.31) that there exist

$$
u^{0}(t)=\lim _{\lambda \downarrow 0} u^{\lambda}(t) \text { strongly in } H^{m+1} \text {, uniformly in } t \in[0, T]
$$

and

$$
u_{t}^{0}(t)=\lim _{\lambda \downarrow 0} u_{t}^{\lambda}(t) \text { strongly in } H^{m}, \text { uniformly in } t \in[0, T]
$$


for any $T>0$. Hence, inequality (1.9) in Remark 1.4 is easily derived from (2.14), (2.31), (2.32) and (2.33).

Furthermore, by (2.31), (2.32) and (2.33),

$$
u^{0}(t)=\lim _{\lambda \downarrow 0} u^{\lambda}(t) \text { weakly in } H^{m+2} \text {, uniformly in } t \in[0, T]
$$

and

$$
u_{t}^{0}(t)=\lim _{t \downarrow 0} u_{t}^{\lambda}(t) \text { weakly in } H^{m+1} \text {, uniformly in } t \in[0, T]
$$

for any $T>0$.

Making use of these convergence properties (2.32)-(2.35), we repeat the arguments in $\S 2.2$ to show that $u^{0}$ is a global solution of $(1.1)_{0}-(1.3)_{0}$ satisfying (1.7), (1.8) and

$$
u^{0} \in C\left([0, \infty) ; H^{m+1}\right) \cap C^{1}\left([0, \infty) ; H^{m}\right) \cap C_{w}^{i}\left([0, \infty) ; H^{m+2-i}\right),
$$

with $i=0,1,2$. On the other hand, Theorem $I$ and the uniqueness result within the class (2.24) enable us to conclude $u^{0} \in C^{i}\left([0, \infty) ; H^{m+2-i}\right)$ with $i=0,1,2$.

In case of $f \in C^{i}\left([0, \infty) ; H^{m+1-i}\right)(i=0,1, \cdots, m)$, we have only to note Proposition 2.1.

[q.e.d.]

Remark 2.3. Recently, A. Matsumura [12] has obtained remarkable results on the existence of global solutions to $(1.1)_{0}-(1.3)_{0}$, while his proof (based on Dionne's result) is very technical. Our proof seems simpler to follow than that of Matsumura, although our existence result (Theorem II (ii)) is almost the same as his.

2.3. Proof of Proposition 2.1

Here it is convenient to use the following notation

$$
D_{x, t}^{\alpha}=\frac{\partial^{|\alpha|}}{\partial_{x_{1}}^{\alpha_{1}} \partial_{x_{2}}^{\alpha_{2}} \cdots \partial_{x_{n}}^{\alpha_{n}} \partial_{t}^{\alpha_{t}}}
$$

where

$$
\alpha=\left(\alpha_{1}, \alpha_{2}, \cdots, \alpha_{n}, \alpha_{t}\right) \text { and }|\alpha|=\alpha_{1}+\alpha_{2}+\cdots+\alpha_{n}+\alpha_{t} .
$$

We shall prove $u^{0} \in C^{i}\left([0, T] ; H^{m+2-i}\right)$ with $i=0,1,2, \cdots, m+2$ by induction. Suppose that

$$
u^{0} \in C^{i}\left([0, T] ; H^{m+2-i}\right), \quad i=0,1,2, \cdots, s,
$$

is true with $s \geqq 2$. Note the next identity 


$$
D_{x, t}^{a} u_{t t}^{0}=\sum_{i, j=1}^{n} D_{x, t}^{\alpha}\left\{a_{i j}\left(\operatorname{grad} u^{0}\right) u_{i j}^{0}\right\}-c D_{x, t}^{\alpha} u_{t}^{0}+D_{x, t}^{\alpha} f,
$$

where multi-index $\alpha$ satisfies $|\alpha| \leqq m$ and $\alpha_{t}=s-1$. Since both $D_{x, t}^{\alpha} u_{t}^{0}$ and $D_{x, t}^{\alpha} f$ belong to $C\left([0, T] ; H^{1}\right) \subset C\left([0, T] ; L^{2}\right)$ by assumptions, it is sufficient to show

$$
D_{x, t}^{\alpha}\left\{a_{i j}\left(\operatorname{grad} u^{0}\right) u_{i j}^{0}\right\} \in C\left([0, T] ; L^{2}\right)
$$

for every $i, j=1,2, \cdots, \mathrm{n}$.

By Leibnitz' formula,

$$
D_{x, t}^{\alpha}\left\{a_{i j}\left(\operatorname{grad} u^{0}\right) u_{i j}^{0}\right\}=\sum_{\beta \leqq \alpha}\left(\begin{array}{c}
\alpha \\
\beta
\end{array}\right) D_{x, t}^{\alpha-\beta}\left\{a_{i j}\left(\operatorname{grad} u^{0}\right)\right\} D_{x, t}^{\beta} u_{i j}^{0},
$$

so that $D_{x, t}^{\alpha}\left\{a_{i j}\left(\operatorname{grad} u^{0}\right) u_{i j}^{0}\right\}$ is written as a linear combination of functions of the form

$$
\left(D_{\eta}^{r} a_{i j}\right)\left(\operatorname{grad} u^{0}\right) \prod_{\ell=1}^{q} D_{x, t}^{s_{\ell}} u_{k_{\ell}}^{0} D_{x, t}^{\beta} u_{i j}^{0}
$$

where $|\beta| \leqq|\alpha|,|\gamma| \leqq|\alpha-\beta|, q \leqq|\alpha-\beta|$ and $\sum_{\ell=1}^{q}\left|\delta_{\ell}\right|=|\alpha-\beta|$.

First we shall show that (2.37) belongs to $L^{2}$ for each $t \in[0, T]$. By assumptions,

$$
D_{x, t}^{\beta} u_{i j}^{0} \in C\left([0, T] ; H^{m-|\beta|}\right)
$$

and

$$
D_{x, t}^{\delta_{\ell}} u_{k_{\ell}}^{0} \in C\left([0, T] ; H^{m+1-\left|\delta_{\ell}\right|}\right) .
$$

Recalling Sobolev's lemma, we may assume $q \geqq 1, m-|\beta| \leqq[n / 2]$ and $m+1-\left|\delta_{\ell}\right| \leqq[n / 2]$ to estimate the $L^{2}$-norm of (2.37). By virtue of Lemma 2.2 (ii) in Chapter I, it follows from (2.38) and (2.39) that

$$
D_{x, t}^{\beta} u_{i j}^{0} \in C\left([0, T] ; L^{p}\right) \text { with } \frac{1}{p} \in\left[\frac{1}{2}-\frac{m-|\beta|}{n}, \frac{1}{2}\right]-\{0\}
$$

and

$$
D_{x, \ell}^{s_{\ell}} u_{k_{\ell}}^{0} \in C\left([0, T] ; L^{p_{\ell}}\right) \text { with } \frac{1}{p_{\ell}} \in\left[\frac{1}{2}-\frac{m+1-\left|\delta_{\ell}\right|}{n}, \frac{1}{2}\right]-\{0\} .
$$

Denote by $1 / P$ and $1 / P_{\ell}$ the infimum of $1 / p$ and $1 / p_{\ell}$ satisfying (2.40) and (2.41), respectively. Then 
80

$$
\begin{aligned}
\frac{1}{P}+\sum_{\ell=1}^{q} \frac{1}{P_{\ell}} & =\left(\frac{1}{2}-\frac{m-|\beta|}{n}\right)+\sum_{\ell=1}^{q}\left(\frac{1}{2}-\frac{m+1-\left|\delta_{\ell}\right|}{n}\right) \\
& =\frac{1}{2}+\frac{n q-2 m-2 q(m+1)+2|\alpha|}{2 n} \\
& \leqq \frac{1}{2}+\frac{q(n-2 m-2)}{2 n} .
\end{aligned}
$$

Since $m \geqq[n / 2]+1$,

$$
\frac{1}{P}+\sum_{\ell=1}^{q} \frac{1}{P_{\ell}}<\frac{1}{2}
$$

Hence there exist some positive numbers $p, p_{1}, \cdots, p_{\ell}$ such that

$$
\frac{1}{p}+\sum_{\ell=1}^{q} \frac{1}{p_{\ell}}=\frac{1}{2}
$$

so that application of Hölder's inequality to (2.37) gives

$$
\begin{aligned}
& \int\left|\left(D_{\eta}^{r} a_{i j}\right)\left(\operatorname{grad} u^{0}\right) \prod_{\ell=1}^{q} D_{x, t}^{\delta_{\ell}} u_{k_{\ell}}^{0} D_{x, t}^{\beta} u_{i j}^{0}\right|^{2} d x \\
& \quad \leqq M_{|r|}\left(\left\|\operatorname{grad} u^{0}\right\|_{\infty}\right)^{2} \prod_{\ell=1}^{q}\left(\int\left|D_{x, t}^{\delta_{\ell}} u_{k_{\ell}}^{0}\right|^{2 \cdot\left(p_{\ell} / 2\right)} d x\right)^{2 / p_{\ell}}\left(\int\left|D_{x, t}^{\beta} u_{i j}^{0}\right|^{2 \cdot(p / 2)} d x\right)^{2 / p} \\
& \quad \leqq C M_{|r|}\left(\left\|\operatorname{grad} u^{0}\right\|_{\infty}\right)^{2} \prod_{\ell=1}^{q}\left\|D_{x, t}^{\delta_{\ell}} u_{k_{\ell}}^{0}\right\|_{m+1-\left|\delta_{\ell}\right|}^{2}\left\|D_{x, t}^{\beta} u_{i j}^{0}\right\|_{m-|\beta|}^{2} .
\end{aligned}
$$

Therefore, we have shown that $D_{x, t}^{\alpha}\left\{a_{i j}\left(\operatorname{grad} u^{0}(t)\right) u_{i j}^{0}(t)\right\}$ with $|\alpha| \leqq m$ and $\alpha_{t}=s-1$ belong to $L^{2}$ for any $0 \leqq t \leqq T$.

It is essentially in the same way as above to prove that

$$
\begin{aligned}
\left\|D_{x, t}^{\alpha}\left\{a_{i j}\left(\operatorname{grad} u^{0}(t)\right) u_{i j}^{0}(t)\right\}-D_{x, t}^{\alpha}\left\{a_{i j}\left(\operatorname{grad} u^{0}\left(t_{0}\right)\right) u_{i j}^{0}\left(t_{0}\right)\right\}\right\| & \longrightarrow 0, \\
\text { as } t & \longrightarrow t_{0},
\end{aligned}
$$

with $|\alpha| \leqq m$ and $\alpha_{t}=s-1$. Consequently we get

$$
u^{0} \in C^{s+1}\left([0, T] ; H^{m+1-s}\right),
$$

which completes the proof.

[q.e.d.]

\section{§3. Asymptotic behavior}

Theorem II asserts the existence of a positive constant $\delta_{0}$ such that, if

$$
\max \left\{\left\|u_{0}\right\|_{m+2},\left\|v_{0}\right\|_{m+1}, \int_{0}^{\infty}\|f(s)\|_{m+1} d s\right\} \leqq \delta_{0}
$$


then the initial value problem $(1.1)_{0}-(1.3)_{0}$ has a unique solution $u^{0} \in$ $C^{i}\left([0, \infty) ; H^{m+2-i}\right)(i=0,1,2)$ satisfying (1.7) and (1.8). Thus, the dissipative term $c u_{t}^{0}(c>0)$ in (1.1) plays a role to stabilize solutions. Moreover, we shall show that this dissipative term has a damping effect on solutions to $(1.1)_{0}$.

\subsection{Proof of Theorem III}

Let $c>0$ and $f \equiv 0$. Let $u^{\lambda}$ be a solution of (1.1) ${ }_{\lambda}-(1.3)_{\lambda}$ satisfying (2.31). Then repeating the arguments in Chapter $\mathrm{I}, \S 5$, we can show

$$
\begin{aligned}
& t\left\{\left\|u_{t}^{\lambda}(t)\right\|_{m+1}^{2}+\left\|\operatorname{grad} u^{\lambda}(t)\right\|_{m+1}^{2}\right\}+\int_{0}^{t} s\left\|u_{t}^{\lambda}(s)\right\|_{m+1}^{2} d s \leqq C, \\
& \quad \text { for all } t \geqq 0 \text { and } 1 \geqq \lambda>0,
\end{aligned}
$$

(cf. (I.5.6)) and

$$
\begin{aligned}
& t^{2}\left\{\left\|\operatorname{grad} u_{t}^{2}(t)\right\|_{m}^{2}+\left\|\Delta u^{\lambda}(t)\right\|_{m}^{2}\right\} \\
& +\int_{0}^{t} s\left\|\Delta u^{\lambda}(s)\right\|_{m}^{2} d s+\int_{0}^{t} s^{2}\left\|\operatorname{grad} u_{t}^{2}(s)\right\|_{m}^{2} d s \leqq C, \\
& \quad \text { for all } t \geqq 0 \text { and } 1 \geqq \lambda>0,
\end{aligned}
$$

(cf. (I.5.13)) with some $C>0$.

On the other hand, convergence properties (2.32)-(2.35) are already known. Thus letting $\lambda \downarrow 0$ in (3.1) and (3.2), we obtain decay estimates (1.10)-(1.13).

[q.e.d.]

3.2. Proof of Corollary

We use the following well-known inequality due to Nirenberg-Gagliardo (see e.g. [15]):

$$
\|u\|_{\infty} \leqq C|u|_{\ell}^{\theta}\|u\|^{1-\theta} \quad \text { for } u \in H^{\ell},
$$

for some $C>0$, where $\ell>n / 2, \theta=n / 2 \ell$ and

$$
|u|_{\ell}^{2}=\sum_{|\alpha|=\ell}\left\|D_{x}^{\alpha} u\right\|^{2}
$$

It follows from (3.3) that

$$
\left\|u^{0}(t)\right\|_{\infty} \leqq C\left|u^{0}(t)\right|_{N}^{\theta}\left\|u^{0}(t)\right\|^{1-\theta},
$$

with $N=[n / 2]+1$ and $\theta=n / 2 N$. Hence, if $N \geqq 2$ (i.e., $n \geqq 2$ ), we have from (1.7), (1.12) and (3.4)

$$
\left\|u^{0}(t)\right\|_{\infty} \leqq C\left|\Delta u^{0}(t)\right|_{N-2}^{\theta}\left\|u^{0}(t)\right\|^{1-\theta} \leqq C\left\|\Delta u^{0}(t)\right\|_{m}^{\theta}\left\|u^{0}(t)\right\|^{1-\theta} \leqq C t^{-\theta},
$$


which shows (1.14) for $n \geqq 2$. If $N=1$ (i.e., $n=1$ ), we see from (1.7), (1.10) and (3.4)

$$
\begin{aligned}
\left\|u^{0}(t)\right\|_{\infty} & \leqq C\left|\operatorname{grad} u^{0}(t)\right|_{N-1}^{\theta}\left\|u^{0}(t)\right\|^{1-\theta} \\
& \leqq C\left\|\operatorname{grad} u^{0}(t)\right\|_{m}^{\theta}\left\|u^{0}(t)\right\|^{1-\theta} \\
& \leqq C t^{-\theta / 2}=C t^{-1 / 4}
\end{aligned}
$$

Other decay estimates (1.15) and (1.16) are derived from (1.10)-(1.13) and (3.4) in the same way as above.

Added in proof. After this paper was submitted for publication, the author was informed of the paper of $\mathrm{H}$. Pecher, "On global regular solutions of third order partial differential equations, J. Math. Anal. Appl., 73 (1980), 278-299". He treats with the global existence of solutions for third-order differential equations which are similar to ours.

\section{REFERENCES}

[1] J. C. Cleménts, On the existence and uniqueness of solutions of the equation $u_{t t}$ $-\left(\partial / \partial x_{i}\right) \sigma_{i}\left(u_{x_{i}}\right)-\Delta_{N} u_{t}=f$, Canad. Math. Bull., 18 (1975), 181-187.

[2] P. L. Davis, A quasilinear hyperbolic and related third-order equations, J. Math. Anal. Appl., 51 (1975), 596-606.

[ 3 ] P. A. Dionne, Sur les problèmes de Cauchy hyperboliques bien posés, J. Analyse Math., 10 (1962), 1-90.

[4] Y. Ebihara, On some nonlinear evolution equations with the strong dissipation, J. Diff. Equations, 30 (1978), 149-164.

[5] — - On some nonlinear evolution equations with the strong dissipation, J. Diff. Equations, 34 (1979), 339-352.

[6] - Some evolution equations with the quasilinear strong dissipation, J. Math. pures et appl., 58 (1979), 229-245.

[ 7 ] J. M. Greenberg, R. C. MacCamy and V. J. Mizel, On the existence, uniqueness, and stability of solutions of the equation $\sigma^{\prime}\left(u_{x}\right) u_{x x}+\lambda u_{x t x}=\rho_{0} u_{t t}$, J. Math. Mech., 17 (1968), 707-728.

[ 8 ] T. Kato, Nonstationary flows of viscous and ideal fluid in $R^{3}$, J. Funct. Anal., 9 (1972), 296-305.

[ 9 ] S. G. Krein, Linear differential equations in Banach spaces, Transl. Math. Monographs Vol. 29, A.M.S., 1971.

[10] J. L. Lions, Quelques méthodes de resolution des problèmes aux limites non linéaires, Dunod Gauthier-Villars, Paris, 1969.

[11] R. C. MacCamy and V. J. Mizel, Existence and nonexistence in the large of solutions of quasilinear wave equations, Arch. Rat. Mech. Anal., 25 (1967), 298-320.

[12] A. Matsumura, Global existence and asymptotics of the solutions of the secondorder quasilinear hyperbolic equations with the first-order dissipation, Publ. RIMS, Kyoto Univ., 13 (1977), 349-379.

[13] —- Energy decay of solution of dissipative wave equations, Proc. Japan Acad., 53 (1977), 232-236.

[14] S. Mizohata, Theory of partial differential equations, Iwanami, 1965 (in Japanese). 
[15] L. Nirenberg, On elliptic partial differential equations, Ann. Scoula. Norm. Sup. Pisa, 13 (1959), 115-162.

[16] O. A. Oleinik, Discontinuous solutions of non-linear differential equations, Uspehi. Math. Nauk, 12 (1957), No. 3, 3-73 (English transl. in A.M.S. Translations Series 2, Vol. 26 (1963), 95-172).

[17] A. Pazy, A class of semilinear equations of evolution, Israel J. Math., 20 (1975), 23-36.

[18] S. L. Sobolev, Applications of functional analysis in mathematical physics, Transl. Math. Monographs Vol. 7, A.M.S., 1963.

[19] M. Tsutsumi, Some nonlinear evolution equations of second order, Proc. Japan Acad., 47 (1971), 950-955.

[20] Y. Yamada, Note on certain nonlinear evolution equations of second order, Proc. Japan Acad., 55 (1979), 167-171.

[21] - Some remarks on the equation $y_{t t}-\rho\left(y_{x}\right) y_{x x}-y_{x t x}=f$, Osaka J. Math., 17 (1980), 303-323.

[22] — , On some quasilinear wave equations with dissipative terms (to appear in Nagoya Math. J., 87 (1982)).

[23] H. Uesaka, The total energy decay of solutions for the wave equation with a dissipative term, J. Math. Kyoto Univ., 20 (1980), 57-65.

[24] A. I. Kozhanov, A mixed problem for a class of nonclassical equations, Differentsial'nye Uravneniya, 15 (1979), 272-280 (English transl. in Differential Equations, 15 (1979), 186-191).

[25] A. I. Kozhanov, N. A. Lar'kin and N. N. Janenko, On a regularization of equations of variable type, Dokl. Akad. Nauk SSSR, 252 (1980), 525-527 (English transl. in Soviet Math. Dokl., 21 (1980), 758-761).

Department of Mathematics

Nagoya University 